In R. Burgess and K. MacDonald (Eds.), Evolutionary Perspectives on Human Development, 2nd edition, pp. 21-72. Thousand Oaks, CA: Sage, 2005.

**This document is an exact copy of the content of the paper. It closely resembles the original in terms of pagination, but it is not exact.

\title{
THEORETICAL ISSUES IN THE STUDY OF EVOLUTION AND DEVELOPMENT
}

Kevin MacDonald and Scott L. Hershberger

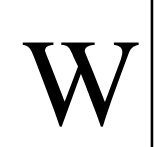

hen the first author wrote the introductory chapter of Sociobiological Perspectives on Human Development (MacDonald, 1988a), the basic approach was to attempt to integrate evolutionary thinking with prominent strands of theory already influential in developmental psychologyparticularly social learning theory, cognitive developmental theory, behavior genetics, and ethology. The intent was not to provide an alternative to these theoretical contributions, but to show how the revolution in evolutionary thinking inaugurated by William Hamilton, Robert Trivers, and G. C Williams and culminating in E. O. Wilson's (1975) Sociobiology could add richness and insight into many areas of developmental psychology.

Whatever the merits of this approach, it soon became eclipsed by a much more radical approach, that of evolutionary psychology (Tooby \& Cosmides, 1992). Evolutionary psychology offered radical critiques of all of the theories that traditionally held sway in developmental psychology. The attempt was not to integrate and amend, but to overthrow and discard. The following describes the program of evolutionary psychology and evaluates its critiques of influential theories of development. The chapter concludes with an updated version of the integrative approach adopted in the 1988 article. An important point is that the big story of childhood is the development of the extraordinary human brain and 
our uniquely human domain-general cognitive abilities, which have resulted in the extraordinary cultural developments of the last several thousand years.

\section{Evolutionary Psychology and Development}

Evolutionary psychologists propose the human mind consists predominantly of highly specialized mechanisms designed to solve specific problems. The specific problems that the human mind is designed to solve are those that repeatedly confronted our ancestors over evolutionary time. When organisms are repeatedly confronted by challenges or opportunities, the optimum response is to develop specialized methods of dealing with them.

The ancestral environment that humans evolved in is termed the environment of evolutionary adaptedness (EEA). This environment consists of a set of problems that must be solved if the animal is to avoid extinction. For example, over evolutionary time, humans and their primate ancestors had to be able find mates and raise children, and they had to form alliances with others. They had to be able to find food, and they had to avoid dangerous predators and poisonous plants and animals. There were a great many other problems that humans had to solve, but the point is that all of these problems presented themselves repeatedly over evolutionary time. According to evolutionary psychology, these problems were solved by evolving a set of psychological mechanisms designed to deal with these specific problems. These mechanisms are adaptations, mechanisms designed by natural selection to solve a particular problem. For example, on the basis of a large body of theory and data, evolutionary psychologists argue that humans evolved mechanisms that allow them to choose mates in an adaptive manner: Women are attracted to men willing to invest in their children, and men are attracted to youthful, physically attractive women because these traits are signs of fertility (e.g., Buss, 1999).

A fundamental premise of evolutionary psychology is that evolutionary adaptations equip animals to meet recurrent challenges of the physical, biological, and social environment. When the environment presents longstanding problems and recurrent cues relevant to solving them, the best solution is to evolve domain-specific mechanisms, or modules, specialized to handle specific inputs and generate particular solutions. Modules are designed to solve problems in specific domains by mapping characteristic inputs onto characteristic outputs (Fodor, 1983, 2000). Their operation is mandatory (i.e., they are automatically triggered in the presence of appropriate environmental stimulation), fast, and unconscious. For example, when we look around the room, our brains are automatically carrying out millions of operations that allow us to see the objects in the room. The calculations are done very rapidly, and we are unaware of them. They carry out their operations by consulting a proprietary 
database. Each module processes information with mechanisms peculiar to its own area of "expertise," so that, for example, verbal and spatial information are processed with different mechanisms. Modules are also information encapsulated: Although information relevant to solving a particular problem may be accessible to other parts of the cognitive system, it is not necessarily available to a module (Fodor, 1983).

The modular view is likely a correct account of how the mind responds to recurrent, highly stable patterns of evolutionarily significant information (Geary \& Huffman, 2002). For example, the three-dimensional structure of the physical world contains a large number of constantly recurring contours (invariances) that have resulted in genetic systems that are sensitive to spatial information related to finding prey and to migration (Gallistel, 1990, 1999).

There are no provisions for responding to variation within categories in the highly constrained modules proposed by Tooby and Cosmides (1992). Geary and Huffman (2002; see also Geary, Ch. 4, this volume) describe "soft modules" as sensitive to accommodating variation within a circumscribed range on analogy with the exoskeleton of invertebrates: The hard exoskeleton responds to invariances related, say, to physical space, language, or the human face, while the soft "innards" respond to variable patterns within a prespecified range. For example, human speech occurs within a genetically specified range, but the system is also open to variant patterns, for example, discriminating the speech patterns of different people.

Developmentally, these soft modules result in biases in children's attentional, affective, and information-processing capacities (Gelman \& Williams, 1998), as well as biases in self-initiated behavioral engagement with the environment, such as play and exploration (Geary \& Huffman, 2002). For example, the proposed face perception module is designed to make babies pay special attention to faces; this results in exposure to information needed to adapt the module to variation in the faces actually seen, such as parents and other family members.

Soft modules go some way toward accommodating traditional developmental theory with approaches derived from evolutionary psychology based on highly constrained modules. Soft modules raise the issue that modules often cannot prespecify the entire range of environmental variation to which they are attuned. Another critical issue is that animals often must find novel solutions to old problems of survival and reproduction. Evolutionary psychologists posit an EEA composed of recurrent cues signaling adaptive dangers and opportunities (Tooby \& Cosmides, 1992). However, this leaves unexplained how humans and many animals are routinely able to solve novel problems and learn novel contingencies. It leaves unexplained how humans have been able to create the 
extraordinary human culture characteristic of the last 50,000 years of human evolution and cope with life in a constantly changing world far removed from our evolutionary past.

Adaptations sensitive to environmental regularities are of critical importance for all animals. However, there is no reason to restrict adaptations to mechanisms responsive to environmental regularities (Chiappe \& MacDonald, 2005). The human EEA contained far more than a set of recurrent cues to dangers and opportunities. Rather, humans were forced to adapt to rapidly shifting ecological conditions by developing adaptations geared to novelty and unpredictability. For example, during the Pleistocene, there were unpredictable and nonrepetitive climatic shifts. There were shifts between cold steppe and warm, forested conditions interspersed with periods of climatic stability (Potts, 1998). These shifts occurred within a century or even decades - far too short a period to evolve adaptations sensitive to environmental regularities.

Moreover, even without a lot of climatic variation, environments are never completely stable and predictable for any animal. Animals and humans often have to make decisions about how to attain their goals in situations where past learning, whether by specialized or unspecialized simple learning mechanisms, is ineffective in attaining evolved goals. For example, rats are able to invent new ways to obtain food rewards by combining information from different sources (Anderson, 2000). Tomasello (1999) notes that most mammals and virtually all primates are able to use insight in learning. For example, ravens are able to solve novel problems by formulating goals, building mental scenarios, and evaluating possible sequences of actions without having to endure their consequences (Heinrich, 2000). The goals are evolutionarily ancient, but the methods used to obtain them do not rely on recurrent environmental cues.

The main criticism rendered by evolutionary psychologists against traditional psychology is that domain-general learning mechanisms are unlikely to have evolved. According to Cosmides \& Tooby (2002), domain-general mechanisms are inherently weak because "jacks of all trades are masters of none. They achieve generality only at the price of broad ineptitude” (p. 170). From their perspective, a basic problem is that there are no particular problems that social learning mechanisms are designed to solve. For example, social learning mechanisms, as described in standard accounts (e.g., Bandura, 1977), have no preset goals and no way to determine when goals are achieved. A child confronted by an aggressive model must have a reason for imitating the model and must have ways of evaluating when the goal is achieved.

This is an example of the frame problem discussed by cognitive scientists (e.g., Dennett, 1987; Fodor, 1983; Gelman \& Williams, 1998). The frame problem is the problem of determining which problems are relevant and what actions are relevant for solving them. A blank-slate organism is unable to 
determine which of the infinite number of problems it must solve to survive and reproduce. Without framing mechanisms guiding it toward the solution of adaptive problems, a problem solver would "go on forever making up solutions that have nothing to do with a non-assigned problem" (Gelman \& Williams, 1998, p. 596). Due to the frame problem, it is difficult to see how domaingeneral processes could evolve. Modular systems, on the other hand, provide a built-in sense of relevance-a built-in sense of what the problem is and how to solve it. They easily solve the frame problem because environmental input is automatically framed by the relevant modules.

The above is a compelling argument for the existence of at least some modular, domain-specific mechanisms. Nevertheless, an important aspect of evolution has been to solve the frame problem in a manner compatible with the evolution of domain-general mechanisms (Chiappe \& MacDonald, 2005; MacDonald, 1991). The basic idea is that humans and other animals have evolved motivational systems that help to solve the frame problem by equipping them with systems that provide signals when their goals are being met. For example, the hunger mechanism provides a signal telling the child to look for food and begin feeding. How the child goes about getting food is unspecified, but the motivational system effectively frames the problem: It tells the child what the problem is (the feeling of hunger), and it tells the child when the problem has been solved (satiation).

From this perspective, a watershed event in evolutionary history was the evolution of psychological signals - positive or negative feelings - that inform the animal when its goals of survival and reproduction are being met or unmet. Imagine a primitive organism equipped only with "if $p$, then $q$ " devices, where $p$ represents recurrent environmental events and $q$ represents an evolved response to the event: If a certain environmental situation $p$ occurs (e.g., presence of food), then respond with behavior $q$ (eating). Such an organism would completely satisfy the requirements for a psychological adaptation as posed by evolutionary psychologists: The mind is constructed with mechanisms designed to respond adaptively to recurrent environmental events. The mechanism is entirely modular, designed to deal exclusively with a particular kind of input and produce a particular kind of output. Its disadvantage would be that there would be no way to take advantage of nonrecurrent information in order to find food, for example, the information that a certain stimulus is a cue for food (classical conditioning), the chance discovery that a certain behavior is a good way to obtain food (operant conditioning), or observing another animal successfully obtaining food (social learning).

Examples of "if $p$, then $q$ " systems are the fixed signaling systems of nonhuman primates and other animals discussed by Oller and Griebel (Ch. 5, 
this volume). Such signals occur in particular contexts (e.g., threat, danger, alarm, greeting) and are coupled to the specific circumstances surrounding their use and the functions they serve. Their meaning is therefore fixed. The breakthrough in human language, however, was to the evolution of contextual freedom, in which each sound can be produced voluntarily and can be coupled, via learning, to an endless variety of social functions. These functions can change quickly over time, making them ideal for dealing with uncertain, novel situations. As in the case of social learning (see below), there is undoubtedly a great deal of specialized neural machinery underlying human language ability. However, like social learning, it functions as a domain-general system, with no evolutionarily fixed inputs or outputs. Even infants 3 to 6 months of age show "complex many-to-many mapping between signal and function, and the signals themselves are produced with great variability, and often with no social function at all” (Oller \& Griebel, Ch. 5, this volume).

The evolution of motivating systems goes a long way toward solving the frame problem. (It is also, quite probably, the evolutionary origin of consciousness, because by definition, the animal must be aware of these motivational cues.) A hungry child may indeed be confronted with an infinite number of behavioral choices, but such a child easily narrows down this infinite array by choosing behaviors likely to satisfy his or her hunger. The motive of hunger, and the fact that certain behaviors reliably result in satiating hunger, give structure to the child's behavior and enable him or her to choose adaptively among the infinite number of possible behaviors. The child's behavior is not random because it is motivated by the desire to assuage the feeling of hunger.

Motivational mechanisms can be thought of as a set of adaptive problems to be solved but whose solution is massively underspecified. Learning mechanisms are examples of the evolution of hyperplastic mechanisms, mechanisms such as the immune system, which are unspecialized because they are not responsive to recurrent environmental events and because there is no selection for a particular phenotypic result (West-Eberhard, 2003, p. 178). Such systems enable the evolution of any cognitive mechanism, no matter how opportunistic, flexible, or domain-general, that is able to solve the problem (Chiappe \& MacDonald, 2005; MacDonald, 1991). The child could solve his or her hunger problem by successfully getting the attention of the caregiver. The problem could be solved if the child stumbled onto a novel contingency (how to open the refrigerator door); or it could be solved by imitating others eating a novel food; or the child could develop a sophisticated plan based on imagining possible outcomes and relying on mechanisms of general intelligence-the $g$ factor of intelligence research. None of these ways of solving the problem need result in solutions that were successful in our evolutionary past. This is illustrated in Figure 2.1. 


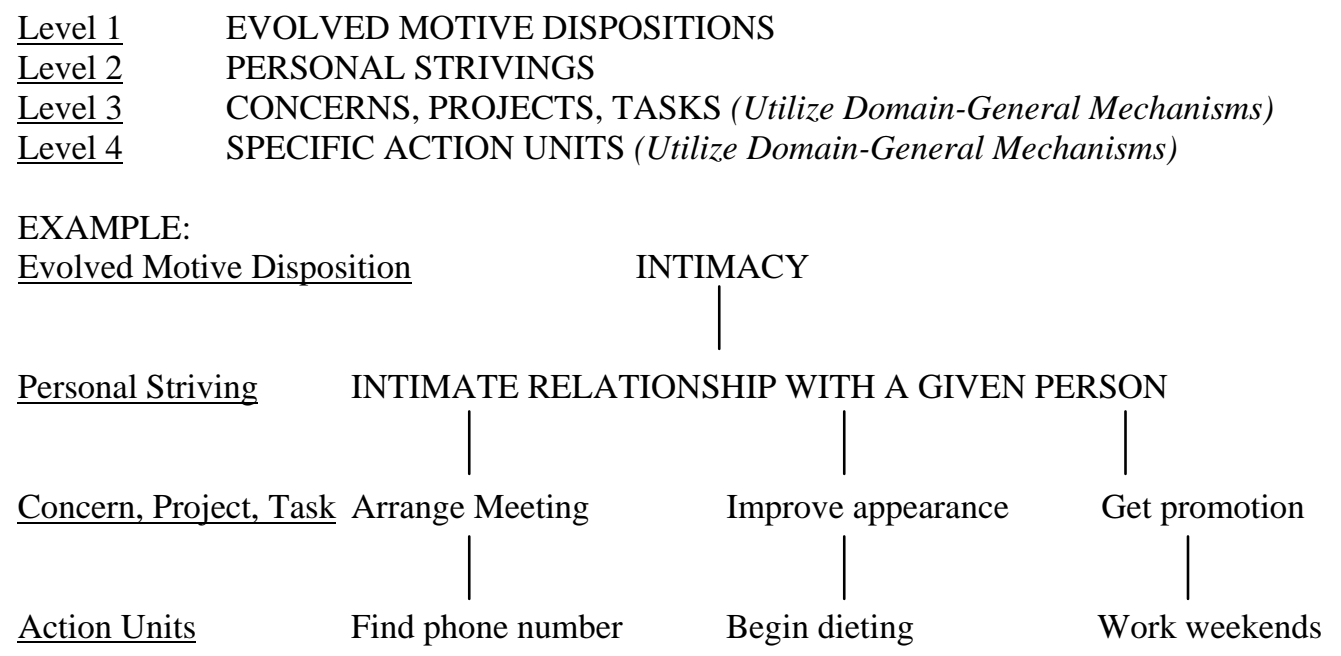

Figure 2.1. Hierarchical Model of Motivation Showing Relationships Between Domain-Specific and Domain-General Mechanisms

SOURCE: Adapted from Emmons (1989)

Motivation represents a major point of contact between evolutionary approaches and approaches based on learning theory. Learning theories generally suppose that some motivational systems are biological in origin, but traditionally they have tended toward biological minimalism. They posit only a bare minimum of evolved motivational systems. For example, traditional drive theory proposed that rats and people have drives to consume food, satisfy thirst, have sex, and escape pain. For an evolutionist, this is a good start, but leaves out 
a great many other things that organisms desire innately. Personality theory provides a basis for supposing there are several evolved motivational systems, including ones for seeking out social status, sexual gratification, felt security (safety), love, and a sense of accomplishment (MacDonald, 1995a, 1998; Ch. 8 this volume). Glenn Weisfeld (1997) has expanded on this list by specifying 16 affects that provide positive or negative signals of adaptive significance: tactile pleasure and pain, thirst, tasting and smelling, disgust or nausea, fatigue, drowsiness, sexual feelings, loneliness and affection receiving, interest and boredom, beauty appreciation, music appreciation and noise annoyance, humor appreciation, pride and shame, anger, and fear. One can quarrel with the details of such a list, but there is little doubt that there are a wide range of positive feelings that humans are innately designed to experience and a wide range of negative feelings that humans are innately designed to avoid.

The pursuit of evolved motives allows for flexible strategizing and the evolution of domain-general cognitive mechanisms-learning mechanisms and the mechanisms of general intelligence useful for attaining evolved desires. This fits well with research showing that problem solving is opportunistic: People satisfy their goals, including evolved goals such as satisfying hunger, by using any and all available mechanisms. For example, children typically experiment with a variety of strategies and then select the ones that are effective. Children are bricoleurs, tinkerers who constantly experiment with a wide range of processes to find solutions to problems as they occur. Children "bring to bear varied processes and strategies, gradually coming through experience to select those that are most effective. . . . Young bricoleurs . . . make do with whatever cognitive tools are at hand” (Deloache, Miller, \& Pierroutsakos, 1998, p. 803).

Indeed, a common evolutionary mechanism for dealing with unpredictability is the initial overproduction of variants followed by selective retention by those that work (West-Eberhard, 2003, p. 41). Overproduction of dendrites followed by synaptic pruning occurs in many brain regions (e.g., stereoscopic depth perception) and is associated with a highly reliable source of environmental information that guides the elimination process (Greenough \& Black, 1992). This experience-expectant information allows the fine-tuning of adaptive systems during a sensitive period, which is defined as the period when excess connections exist. This also fits well with Thelen's (1995) findings on motor development: Babies initially produce a wide range of unfocused movements, followed by selective retention of movements that are effective in attaining goals. Such mechanisms are adaptive because the outcome of the selection process is not genetically transmitted; flexibility is not diminished between generations.

The following sections discuss social learning theory, cognitive developmental theory, behavior genetics, and ethology. Each section includes 
the critique made by evolutionary psychologists, an evaluation of the critique, and a discussion of the theory from the integrative perspective developed here. A major theme is that general intelligence and the big brain that it entails are the central facts of human development-that the contours of human development are shaped by the requirements of producing a large-brained organism with the most powerful domain-general mechanisms known to nature.

\section{Social Learning Theory}

Social learning theory remains an important theoretical approach in developmental psychology (see also Flinn, Ch. 3, this volume). The critique proposed by evolutionary psychology emphasizes that social learning cannot be truly domain-general because it requires,

A rich battery of domain-specific inferential mechanisms, a faculty of social cognition, a large set of frames about humans and the world drawn from the common stock of human metaculture, and other specialized psychological adaptations designed to solve the problems involved in this task. (Tooby \& Cosmides, 1992, p. 119)

The critique of social learning theory therefore emphasizes the need for domain-specific mechanisms as a precondition for social learning. Social learning no doubt requires a great deal of evolved machinery; otherwise, it would be far more common among animals. Indeed, Tomasello (1999) emphasizes the uniqueness and incredible power of human social learning as deriving from an adaptation for the ability to engage in joint attention at around 9 months of age. This allows humans to see others as having goals and selecting among possible alternatives, thereby allowing them to take advantage of the way others have achieved their goals.

However, even if one accepts the premise that certain domain-specific mechanisms are prerequisites for social learning, this is insufficient to establish social learning as domain-specific. To be interesting, the argument must entail that the content of what is learned is evolutionarily circumscribed, and there is no evidence that this is the case. Evolved biases are indeed important in social learning, as emphasized in the original version of this chapter (MacDonald, 1988a; see also below). However, this does not imply that social learning evolved to solve a particular, highly discrete problem recurrent in the EEA. There is no evidence at all that the information available to social learning mechanisms or transmitted by social learning mechanisms is restricted to a specific set of messages important for adaptation in the EEA. We can use social 
learning to learn how to fix TV sets as easily as for learning how to hunt for wild boars. Social learning systems in humans are domain-general in the critical sense that they allow us to benefit from the experience of others, even when their behavior was not recurrently adaptive in the EEA, but is effective in achieving evolved goals in the current environment.

For humans, the types of behaviors that can be successfully transmitted by social learning are not limited to behaviors useful to meeting recurrent challenges of the EEA. They are limited only by general cognitive and motor limitations: limitations on the informational complexity of modeled behavior, limits on attentional processes and memory, and limitations on human motor abilities (Bandura, 1969, 1977; Shettleworth, 1994). Even among rats, Kohn and Dennis (1972) found that animals that were able to observe other rats solve a discrimination problem (and thus avoid shock) were quicker to learn this discrimination than rats that were prevented from the opportunity to observe. The patterns that were discriminated were entirely arbitrary and in no sense elements of the EEA. The response pattern involved motor activity to escape the shock by going through the appropriate door. The mechanism therefore was not domain-specific: It was not triggered by a highly delimited stimulus recurring in the EEA and it did not result in a highly discrete response designed specifically to deal adaptively with this problem.

In general, we expect that domain-general learning will be most important in highly variable environments (Boyd \& Richerson, 1985, 1988). The reason for this is that when environments change rapidly, it is not possible for an animal to track the changes genetically. Domain-specific, modular mechanisms evolve by tracking environmental cues that recur over and over again across generations, as in the example of three-dimensional space mentioned above. Animals must accommodate to a three-dimensional world repeatedly, over many generations, and the input useful for tracking this world is the same as it was in the EEA. On the other hand, if the usefulness of a particular behavior is only transient or local, there would be no possibility (or need) for the evolution of a genetic system devoted to producing this behavior.

We also expect that domain-general learning devices will evolve if there are low costs to learning. On the other hand, natural selection has sometimes molded learning mechanisms away from domain-generality if the costs of domain-general learning are too high (Garcia \& Koelling, 1966; Öhman \& Mineka, 2001; Rescorla, 1988). A good example is taste aversion learning in a wide range of species, including quail, bats, catfish, cows, coyotes, and slugs (Kalat, 1985). If a rat consumes food and later feels nauseous, it associates the illness with the food rather than with other more recent stimuli such as lights and sounds, and it will make this association over much longer periods of delay than is typical for other examples of learning. The association of food with 
poison is greatly influenced by whether the food is unfamiliar to the animal. This indicates that taste aversion learning in rats is an adaptation to nonrecurrent and unpredictable features of the environment.

In this case, novel food items are a potential resource for the animal and must not be ignored even though they are more likely to be dangerous. Novel food items were a recurrent but unpredictable feature of the rat's EEA, with the result that the animal has evolved adaptations that minimize the cost of sampling this novelty. Because domain-general learning in this case is so costly, evolution has designed a constrained, biased learning mechanism. Rats preferentially eat novel food that they have smelled on the breath of another rat (Galef, 1987), thereby minimizing the danger of trial-and-error learning. This shows the utility of specialized social learning mechanisms that evolved to adapt to recurrent problems involving specific sources of novelty.

There are many recurrent but contingent aspects of an animal's microenvironment that must be learned. This learning is best performed by specialized learning mechanisms that allow for rapid and efficient learning of specific types of information. For example, there are specialized mechanisms that allow children to learn language (Oller \& Griebel, Ch. 5, this volume). The language acquisition device makes learning any human language an effortless task, whereas the task is impossible for animals not so equipped. There certainly are mechanisms that make possible learning certain types of recurrently important information. However, it does not follow that the language acquisition device or other "learning instincts" (Tooby \& Cosmides, 1992) should be viewed as a general paradigm for all human learning or even that language learning itself does not exhibit aspects of domain-generality (Oller \& Griebel, Ch. 5). Language acquisition is more the exception than the rule in human learning. Unlike social learning and associative learning, there is a critical period for language, during which it is most efficient (Pinker, 1994; Spelke \& Newport, 1998). Moreover, the capacity to acquire language can be selectively impaired. Children with specific language impairment have normal intelligence, but their ability to acquire language is disrupted (Pinker, 1994). However, not all forms of learning can be selectively impaired, suggesting at least some learning mechanisms apply to a wide range of domains.

Domain-generality is apparent in Pavlovian conditioning and instrumental conditioning in animals and humans (Chiappe \& MacDonald, 2005). Both systems allow animals and humans to make opportunistic associations between local, transient events not recurrent in their EEA. As mentioned above, there are well-documented cases where there are evolved biases away from domaingenerality, as in taste aversion learning in rats (e.g., Garcia \& Koelling, 1966; Rescorla, 1980). In general, however, animals rely on "rules of thumb” based on 
very broad, general features of the environment. For example, in Pavlovian conditioning, the main general predictors are contiguity (including temporal order and temporal contiguity) and contingency (reliable succession). These predictors reflect the fact that causes are reliable predictors of their effects, that causes precede their effects, and that in general causes tend to occur in close temporal proximity to their effects (Revulsky, 1985; Staddon, 1988). Causes that are temporally far removed from their effects are difficult to detect, and the temporal contiguity of cause and effect is a general feature of the world. The fact that there are exceptions, as in taste aversion learning, where noncontiguous causes have a special status because of the evolutionary history of the animal, does not detract from the general importance of temporal contiguity. From the animal's perspective, in the absence of such a prepared association, the best default condition is to suppose that causes precede the unconditioned stimulus and are temporally contiguous. While temporal contiguity is neither a necessary nor a sufficient condition for associating events, in general, it is a main source of information on causality (Shanks, 1994).

Tooby and Cosmides (1992) claim that support for domain-generality in learning relies on data from "experimenter-invented, laboratory limited, arbitrary tasks” (p. 95). They criticize traditional learning experiments for not focusing exclusively on ecologically valid, natural tasks - tasks that deal with problems that were recurrent in the animal's EEA. Such a stance obviously begs the question of whether there are nonrecurrent problems that can be solved by learning. While it is certainly true that investigations of such tasks are likely to reveal specialized learning mechanisms in some cases, an equally remarkable aspect of learning is that pigeons can learn to peck keys to satisfy their evolved goals of staving off hunger and eating tasty foods even in experimentercontrived situations. Although pecking for food is undoubtedly a species-typical behavior for pigeons, pigeons, like rats learning to push levers, are also able to learn a variety of arbitrary, experimenter-contrived behaviors that are not components of the animal's species-typical foraging behavior. In other words, they are able to solve a fundamental problem of adaptation (getting food) in a novel and even arbitrary environment that presents few, if any, of the recurrent associations between the animal's behavior and obtaining food experienced in the animal's EEA. Similarly, humans are able to learn lists of nonsense syllables — another example highlighted by Tooby and Cosmides (1992), despite the fact that learning such lists was not a recurrent problem in the EEA. People can learn such lists because their learning mechanisms can be harnessed to new goals, such as getting course credit as a subject in a psychology study.

In general, neither operant nor classical conditioning evolved to exclusively link specific events or behaviors recurrent in the EEA. The mechanisms underlying these abilities imply a great deal of evolved machinery, and there are 
important cases where evolution has shaped learning in ways that depart from domain-generality. In general, there is no characteristic input to these systems, because the input to associational mechanisms of rats and humans verges on whatever is detectable by the sense organs, and operant behaviors span virtually the entire range of physically possible motor behaviors. Because of their domain-generality, these mechanisms allow humans to solve problems with features not recurrent in the EEA.

There are important evolved mechanisms guiding human social learning in adaptive ways. Parent-child affection channels children's social learning within the family (MacDonald, 1992, 1997a). The human affectional system is designed to cement long-term relationships of intimacy and trust by making them intrinsically rewarding (MacDonald, 1992). A continuing relationship of warmth and affection between parents and children is expected to result in the acceptance of adult values by the child, identifying with the parent, and a generally higher level of compliance: "the time-honored concept of warmth and identification” (Maccoby \& Martin, 1983, p. 72). The finding that warmth of the model facilitates imitation and identification has long been noted by social learning theorists (e.g., Bandura, 1969).

Domain-general learning mechanisms interact with other personality systems. For example, the fear system illustrates the complex interplay between domainspecificity and domain-generality (see LaFreniere, Ch. 7, this volume). The fear system is selective in its inputs: Certain stimuli recurrently associated with danger in the EEA are particularly easy to acquire and difficult to extinguish (e.g., Öhman \& Mineka, 2001; Seligman, 1971). However, other stimuli can gain control of the fear system. The adaptiveness of domain-general aspects of the fear system can be seen from data showing that when the unconditioned stimulus is highly aversive or when a conditioned stimulus without any evolutionary significance is known to be very dangerous, the differences between evolutionarily primed fears and nonevolutionarily primed fears disappear (Chiappe \& MacDonald, 2005; Öhman \& Mineka, 2001, p. 513). As a result, intense trauma may result in phobias even toward normally benign objects with no evolutionary prepotency (Campbell, Sanderson, \& Laverty, 1964; Lautch, 1971). This modification of the fear system by what one might term "system-specific stimulation" is quite likely a general phenomenon in personality (Segal \& MacDonald, 1998; see Ch. 8, this volume). 


\section{Piagetian Psychology and Information Processing}

Research in cognitive development reveals an important role for the types of modular architecture posited by evolutionary psychologists as central to human cognition (e.g., Bjorklund \& Pellegrini, 2002; Gelman \& Williams, 1998). The 1988 chapter highlighted aspects of Piagetian theory that are consonant with an evolutionary perspective:

1. Intrinsic motivation: the child as a curious and interested explorer of the world rather than a passive recipient of environmental influences. The pleasure infants feel when they solve problems and understand the world a bit better is another example of the affective motivational mechanisms discussed above as critical to the evolution of domain-general cognitive mechanisms.

2. There are universal features of human social development and universal, age-graded differences among children. These universal features are products of human genetic invariance, the common human genetic heritage, interacting with universal features of the environment. The universal features of the pan-human EEA include the world of three-dimensional objects and very general features of the social world common to all human groups.

The 1988 chapter reflected the criticisms of stage theories that were already current at that time (Flavell, 1985; Gelman \& Baillargeon, 1983), but the domain-general nature of Piagetian stages was not proposed as an important problem. This is because domain-generality itself was not seen as necessarily incompatible with an evolutionary perspective, as indeed it is not. In recent years, neo-Piagetian stage models incorporating modular, domain-specific mechanisms along with nonmodular, domain-general mechanisms have been elaborated. Case (1998) describes domain-general central conceptual structures (CCS) that serve to integrate and organize information from modular systems of number, space, and theory of mind: "Although the content that they serve to organize is modular, the structures themselves reflect a set of principles and constraints that are systemwide in their nature, and that change with age in a predictable fashion” (p. 770). Among the factors thought to be important for stage advances in CCS is working memory, a domain-general ability that is also implicated in the model of Demetriou, Christou, Spanoudis, and Platsidou (2002). Their model includes domain-general abilities revealed by research in the tradition of IQ testing (speed of processing, working memory, and attentional control), lower-level, domain-specific ability modules (quantitative/relational, spatial/imaginal, verbal/propositional, qualitative/analytic, and causal/experimental), and stage transitions, that is, transition zones in which there are major developmental changes in these domain-specific and domain-general abilities (see Figure 2.2). 


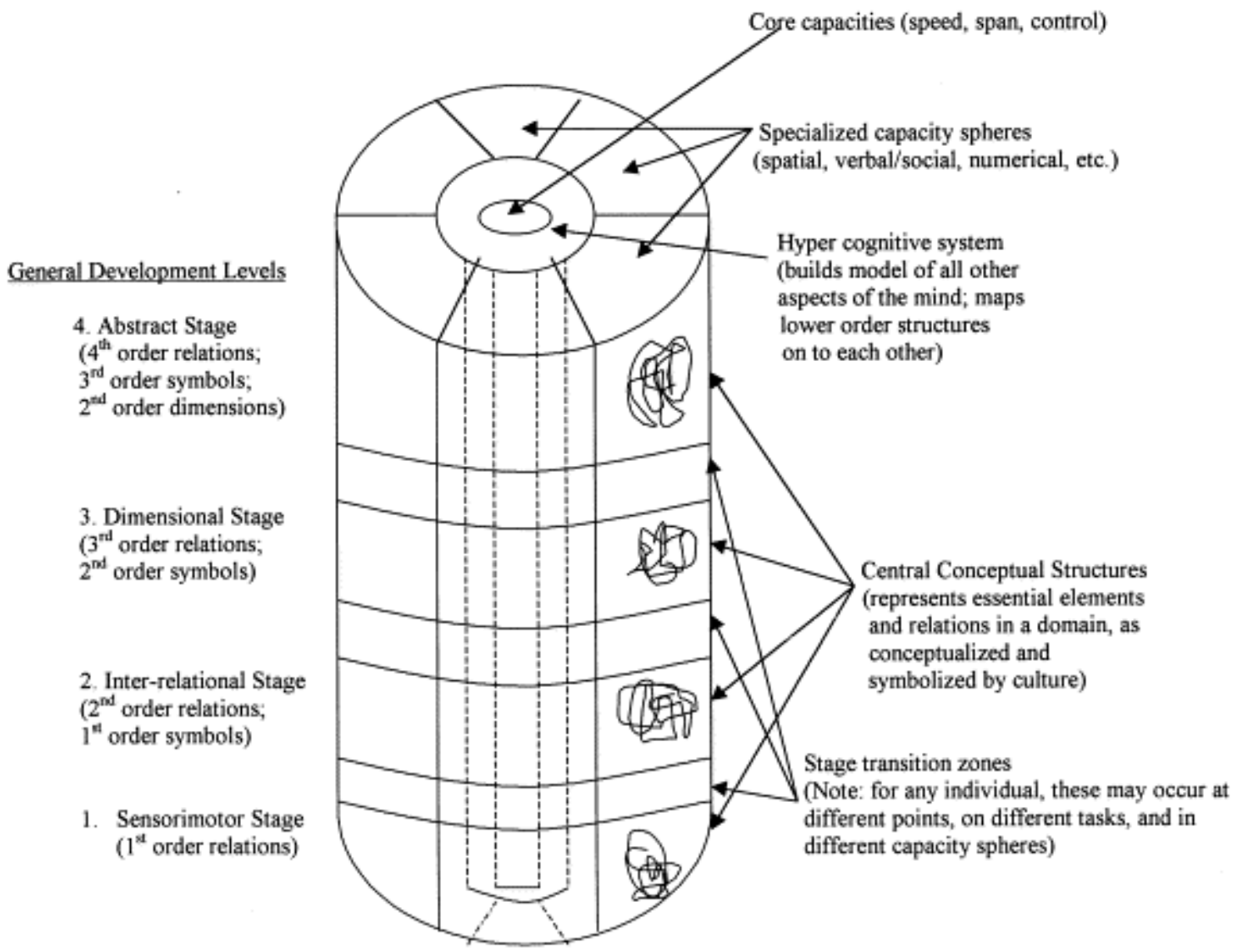

Figure 2.2. Integrated Model of the Developing Mind

SOURCE: From Demetriou, Efklides, and Platsidou (1993). Copyright: Society for Research in Child Development. Reprinted with permission.

NOTE: The Core Capacities are domain-general abilities; the Specialized Capacity Spheres are modular abilities.

These models illustrate the continued power of models integrating both domain-general and domain-specific mechanisms. Both domain-general and domain-specific systems are supported, and both are compatible with the importance of stage-like transitions. It is noteworthy that these models integrate 
the modular, domain-specific mechanisms of the information-processing tradition with mechanisms of working memory, speed of processing, and inhibitory ability discovered to underlie general intelligence in the psychometric tradition. Indeed, in a study combining standard IQ tasks (the WISC) with neoPiagetian tasks, Case, Demetriou, Platsidou, \& Kazi (2001) found support for the five domain-specific abilities noted above (quantitative/relational, spatial/imaginal, verbal/propositional, qualitative/analytic, and causal/experimental) as well as for a general intelligence factor representing the correlations among all of these subfactors. (See Figure 2.3.) The specific abilities have their own evolutionary histories, unique set of underlying operations, and unique logic_-hallmarks of evolved modules.

At the same time, the general intelligence factor, $g$, was more robust when age effects were included, suggesting that changes in $g$ are the main factor responsible for developmental shifts in mental ability.

Although there may be additional sources of variability in children's reasoning on Piagetian tasks, the sources of variability isolated by psychometric theorists are powerful because they differentially affect the rate at which children construct new conceptual understandings in many of the different fundamental areas identified by Kant: areas such as space, number, causation, and social cognition. (Case et al., 2001)

Supporting the importance of age changes in domain-general processes, Kail (1996) has shown that developmental increases in speed of processing is a critical mechanism of children's cognitive development, linked to increases in working memory and increases in performances on IQ instruments such as the Raven's Progressive Matrices. In a later section, I will argue that the most important story of human development - the reason why human development takes so long and why children require so much adult investment in time and energy - is the maturation of the brain's information-processing capabilities and specifically, the structures underlying general intelligence.

There is excellent evidence that general intelligence is an adaptation underlying the ability of humans to create novel solutions to ancient problems of survival and reproduction (Chiappe \& MacDonald, 2005; Geary, Ch. 4, this volume). From an evolutionary perspective, a critical function of general intelligence is the attainment of evolutionary goals in unfamiliar and novel conditions characterized by a minimal amount of prior knowledge. Tests of Cattell's (1963) fluid intelligence, such as Raven's Progressive Matrices and Cattell's Culture Fair Test, are strongly associated with the ability to solve novel problems (Horn \& Hofer, 1992). They reflect the capacity “to adapt one's 


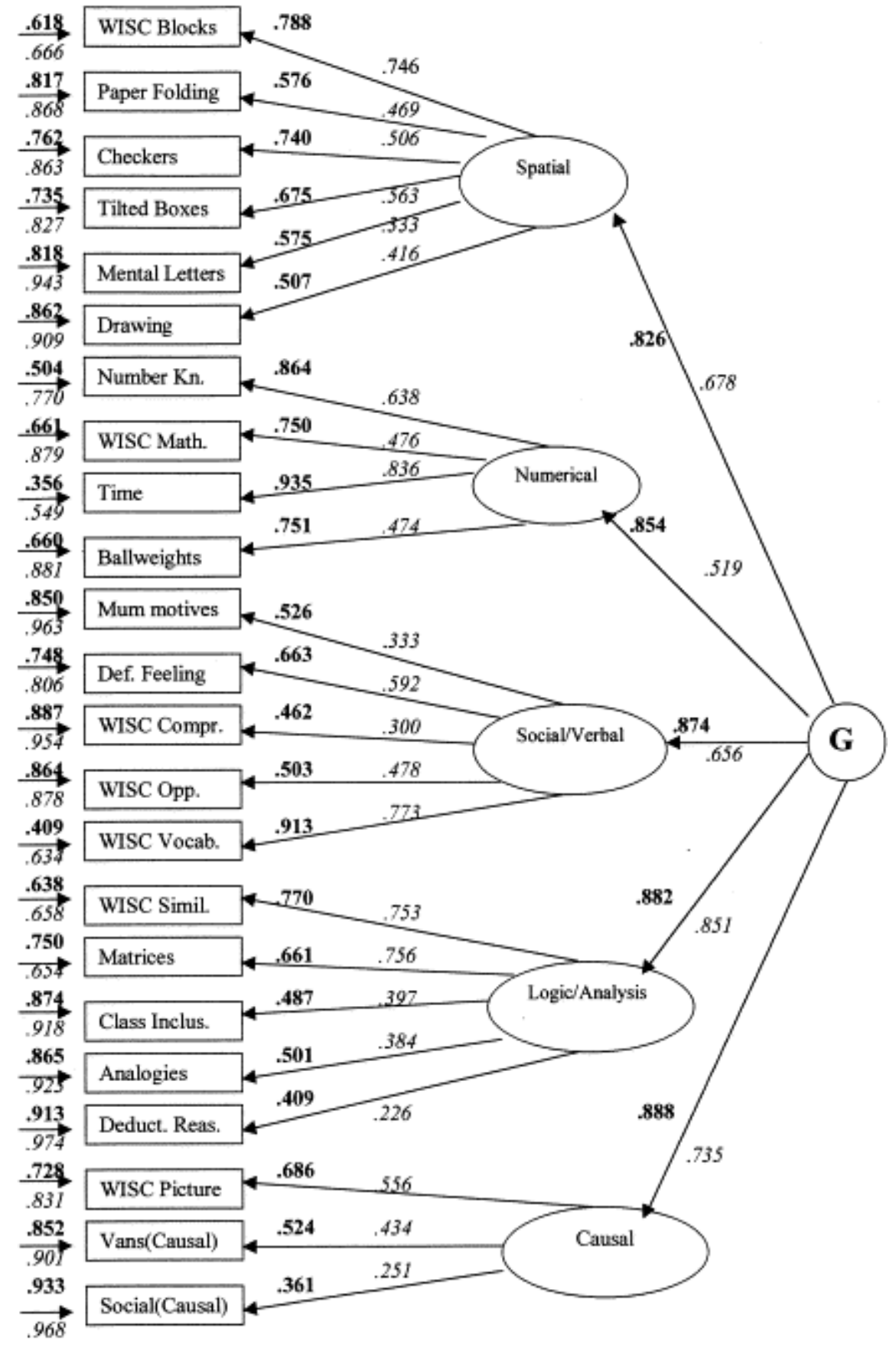

Figure 2.3 Hierarchical Model of Intelligence, With Modular Abilities Arrayed Under the General Intelligence Factor SOURCE: From Case et al. (2001). Copyright 2001, Elsevier. Reprinted by permission 
thinking to a new cognitive problem” (Carpenter, Just, \& Shell, 1990, p. 404). Fluid intelligence lies at the heart of the concept of $g$. As several researchers have pointed out, tests of fluid intelligence produce the highest $g$ correlations (Carpenter et al., 1990; Carroll, 1993; Duncan, Burgess, \& Emslie, 1995; Duncan, Emslie, Williams, Johnson, \& Freer, 1996).

Research on intelligence has consistently found that more-intelligent people are better at attaining goals in unfamiliar and novel conditions characterized by a minimal amount of prior knowledge. People with high intelligence have a variety of real-world advantages (Gottfredson, 1998; Herrnstein \& Murray, 1994). They tend to make more money and achieve a higher social status than people on the low end of the IQ distribution. The $g$ factor is the best single predictor of job performance. Correlations between $g$ and job performance range between 0.2 and 0.8 , with greater predictive validity achieved for jobs of greater complexity. Thus, people with higher intelligence are more adept at attaining their evolutionary goals in situations of novelty, complexity, and unpredictability-precisely the functions of $g$ as a psychological adaptation designed by natural selection (Chiappe \& MacDonald, 2005; Geary, Ch. 4, this volume).

General intelligence is therefore at the heart of an evolutionary analysis. Although modules designed to process specific types of information are unquestionably important to an evolutionary analysis, evolutionary psychology has overemphasized modularity and ignored the vast data indicating a prominent role for domain-general mechanisms in human and animal cognition. Domaingeneral mechanisms are not weak "jacks of all trades but masters of none," as evolutionary psychologists would have it. They are powerful but fallible mechanisms that are the basis for solving a fundamental problem faced by all but the simplest organisms: the problem of navigating constantly changing environments that present new challenges that have not been recurrent problems in the EEA. Most important, the domain-general mechanisms at the heart of human cognition are responsible for the decontextualization and abstraction processes critical to the scientific and technological advances that virtually define civilization (Chiappe \& MacDonald, 2005).

\section{The Developmental Systems}

\section{Perspective and Behavior Genetics}

The 1988 introductory chapter contained no mention of developmental systems theory (DST) associated most prominently with Gilbert Gottlieb (1992; 
Gottlieb, Wahlsten, \& Lickliter, 1998; see also Lickliter \& Honeycutt, 2003) because it did not seem compatible with the findings of behavior genetic research or with a modern evolutionary perspective. Because of its focus on universal adaptations, evolutionary psychology has also shown no interest in behavior genetics or, indeed, individual differences in general—conceptualizing individual differences as "noise" without adaptive significance (Tooby \& Cosmides, 1992).

However, there are good theoretical reasons to suppose that natural selection has shaped the enormous interest people have in individual differences in personality and other types of individual differences (e.g., intelligence) (Lusk, MacDonald, \& Newman, 1998; MacDonald, 1995a, 1998, and Ch. 8, this volume). People choose mates, friends, allies, and leaders based partly on their personalities. Reflecting the importance of personality as a resource in human transactions, people often go to great lengths to convince others of their personal qualities (e.g., their honesty and intellectual competence), processes that often involve deception and self-deception. Behavior genetics, as the science of understanding the genetic and environmental influences on human diversity, is thus central to an evolutionary approach to development. Also, because different human groups evolved in somewhat different EEAs, understanding betweengroup genetic variation will shed light on the origins of human differences, for example, the tendency for children from the Mongoloid gene pool to be lower on affect intensity, aggression, and disruptiveness, and to be more cooperative than Caucasian children (Brazelton, Robey, \& Collier, 1969; Freedman \& Freedman, 1969; Orlick, Zhou, \& Partington, 1990).

DST is a prominent opponent of behavior genetic analysis. It deserves scrutiny because of its widespread influence within developmental psychology (as indicated, e.g., by its prominence in Richard Lerner's, 1998, edited volume in the authoritative Handbook of Child Psychology series) and because it forms the theoretical basis of Bjorklund and Pellegrini's (2002) recent attempt to reconcile evolutionary psychology and human development.

As represented in Figure 2.4, DST proposes that there are reciprocal influences at all levels of development, from genes to the environment. Development occurs in a set of hierarchically organized systems of increasing size, differentiation, and complexity, in which each component affects, and is affected by, all the other components, not only at its own level but at lower and higher levels as well. Genes do indeed influence physiology, behavior, and the environment, but the reverse also occurs: The external environment influences behavior, which influences physiology, and eventually turns particular genes on and off. The result is "a totally interrelated, fully coactional system in which the activity of the genes themselves can be affected through the cytoplasm of the 


\section{BIDIAECTIONAL INFLUENCES}

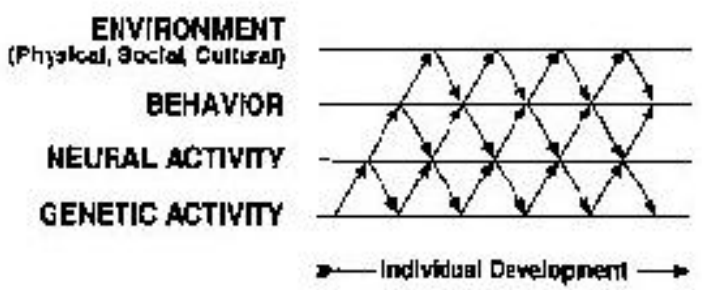

FIG. b.1. The prohabilistic epibenets conceptual framework shoving a hierarchy of four mutually coscting levele of snilytelt in which thers are "top down" as rell as "bottom-up" bidirectional influences. From Individusl Devebopment and Evolution: The Gernesis of Novel Bthivior by Gilbert Gottieb. Copyright * 1991 by Oxford Untversily Press. Inc. Reprinted by permisstar.

Figure 2.4. Gottlieb’s Model of Bidirectional Influences

SOURCE: From Individual Development and Evolution: The Genetics of Novel Behavior, by Gilbert Gottlieb. Copyright 1991 by Oxford University Press. Reprinted by Permission.

cell by events originating at any other level in the system, including the external environment" (Gottlieb, 1992, p. 145).

Gottlieb regards his theory as incompatible with the reaction range idea and with behavioral genetic research in general. The common response of behavioral geneticists to Gottlieb's theory is a mixture of outrage combined with charges of fundamental misunderstandings and suggestions of political motivation (e.g., Turkheimer, Goldsmith, \& Gottesman, 1995). All sides agree that there are complex interactions among genes and environments and that environments affect genetic activity - that, for example, genes are turned on and off during development by exposure to environmental stimulation.

It is important to have a concept of an evolutionarily expected environment (EEE) and the closely related concept of the EEA. These concepts, originating with Bowlby (1969), highlight the idea that species are designed to solve the problems encountered in the environments in which they evolved, and animals are designed to expect the range of environments typically encountered during their evolution. Gottlieb's argument rests on "what if" theorizing that stresses the unpredictable and unusual effects of major deviations from the expected environment (Scarr, 1995). Evolutionary approaches ranging from evolutionary psychology (Tooby \& Cosmides, 1992) to the developmental systems approach of Bjorklund and Pellegrini (2002) to the integrative approach discussed here 
suppose that it is meaningful and important to speak of a universal, speciestypical environment: the environmental invariance that, as noted in the above discussion of cognitive developmental theory, combines with normal human genetic commonality to result in reliably developing human phenotypes. Gottlieb's theory is profoundly antievolutionary because it ignores the actual evolution of developing systems - the typically encountered environmental problems that these systems were designed to solve. Recurrent environmental events are a critical force in evolution:

It is only those conditions that recur, statistically accumulating across many generations, that lead to the construction of complex adaptations.... For this reason, a major part of adaptationist analysis involves sifting for these environmental or organismic regularities or invariances. (Tooby \& Cosmides, 1992, p. 69)

While this statement goes too far in emphasizing the importance of environmental invariance for designing adaptations (Chiappe \& MacDonald, 2005), there is no question that a fundamental aspect of evolution is the design of adaptive systems in response to environmental regularities. By ignoring environmental invariance, Gottlieb effectively undercuts the entire concept of an adaptation.

This same objection applies as well to Lickliter and Honeycutt's (2003) critique of evolutionary psychology from the standpoint of DST. If development were truly as contingent and unspecified genetically as these authors claim, there would be no way to explain the overwhelming regularity of developmental outcomes: the fact that development within the normal range of human environments reliably results in normally formed, psychologically functioning children.

Bjorklund and Pellegrini's (2002) acceptance of the standard evolutionary concept of an EEE goes some way toward providing a minimally acceptable evolutionary theory of development. However, they accept Gottlieb's ideas that genetic and environmental sources of individual differences cannot be literally partitioned via the standard techniques of behavioral genetics, and they claim that Gottlieb is correct in arguing that behavior genetic research provides an overly simple characterization of the environment (p. 79). At the same time, they propose that "we believe that the expression of many genes that influence individual differences is robust to the perturbations of a wide range of 'ordinary' environments, accounting for the impressive predictions of behavior genetics" (p. 85). But such a claim is exactly what is embedded in the concept of additive genetic variance that has been shown to be the most important genetic contribution to individual differences: Additive genes have their effect in a wide range of environments typically encountered by the organism. There is no reason whatever to avoid studying such genes or to reject the idea of partitioning 
the components of variance, as is done in standard behavior genetics research.

Gottlieb’s (1995) “norm of reaction” concept implies that "it is not possible to predict outcomes from one rearing circumstance to the next” (p. 133). Gottlieb also argues that the reaction range idea sets "strict and predictable upper and lower limits for a genotype” (p. 134). At the heart of Gottlieb's theory is the idea that complex, idiosyncratic interactions with environments are the rule rather than the exception (also apparent in Lickliter \& Honeycutt, 2003), with the result that development is unpredictable, apparently implying that parents really couldn't have any good reason to suppose that talking to their children and taking them to museums would be a better way to treat them than locking them in a closet.

Gottlieb's theory implies that the concept of additive genetic variance is vacuous, and although Gottlieb embraces average effects of environments, his position of omnipresent interactions implies that there are no expectable average effects of rearing in different environments. All of these propositions are incorrect. In fact, Gottlieb does not provide a single study from the human psychological literature showing that there are high levels of genotypeenvironment interactions within normal ranges of environmental variation. The single animal example discussed in Gottlieb involves both artificial selection for maze learning and extreme rearing conditions and thus says nothing about the importance of genotype-environment interaction in natural populations within the range of the EEE. Even using extreme environments under controlled conditions, animal studies have typically not shown an important contribution of genotype-environment interaction (Rutter \& Silberg, 2002).

As conceptualized by Gottlieb and others, GXE occurs when the effects of the environment depend on genetic differences among individuals. This definition of GXE is comparable to the definition of an interaction in the analysis of variance: The effect of one independent variable (genotypic differences) on a dependent variable (phenotypic differences) varies as a function of a second independent variable (environmental differences). GXE can be represented schematically as a $2 \times 2$ factorial arrangement in which one variable is the genotype and the other is the environment (see Figure 2.5). For any dependent variable, the design can be used to investigate the effect of genotype independent of the environment (i.e., the genetic main effect or the heritability of the dependent variable), the effect of the environment independent of genotype (i.e., the environmental main effect or the environmentality of the dependent variability), and GXE. One example of GXE could be that a child having a high genetic value for introversion may be moderately interactive with a small group of friends but very inhibited within a large group of unfamiliar children, whereas a child having a low genetic value for introversion (i.e., extraversion) may be uninhibited in both situations. 
$\mathrm{G}_{1}$

$\mathrm{G}_{2}$

\begin{tabular}{|l|l|}
\hline $\mathrm{E}_{1}$ & \\
\hline $\mathrm{G}_{1} \mathrm{E}_{1}$ & $\mathrm{G}_{2} \mathrm{E}_{1}$ \\
& \\
\hline $\mathrm{E}_{2}$ & \\
\hline & \\
$\mathrm{G}_{1} \mathrm{E}_{2}$ & $\mathrm{G}_{2} \mathrm{E}_{2}$ \\
\hline
\end{tabular}

Figure 2.5. Genotype-Environment Interaction in the Form of 2 x 2 Analysis of Variance (ANOVA)

We believe that GXE is of dubious importance for explaining individual differences in human behavior. Our belief is based on two considerations: (1) the vast empirical evidence against the significance of GXE and (2) the inconsistency of GXE and evolutionary theory. To more clearly communicate why GXE is a trivial source of variance, we first describe the model underlying most quantitative investigations of phenotypic variation. In the simplest form of the model, a phenotype (P) is a linear function of genetic (G) and environmental (E) causes. However, because the purpose is to explain the variance of a phenotype, $\mathrm{G}$ is expressed as a deviation score from the genotypic mean, and $\mathrm{E}$ is expressed as a deviation score from the environmental mean, while allowing for the possibility of genotype-environment interaction ( $\mathrm{G} \mathrm{X} \mathrm{E)}$ and random error (e):

$$
\mathrm{Pi}=\mathrm{Gi}+\mathrm{Ei}+(\mathrm{GXE}) \mathrm{i}+\mathrm{ei}
$$

where the $i$ refers to the ith individual's deviation from the mean.

$G$ can be partitioned further into three separate elements, each expressed as a deviation score - the additive genetic deviation (A), the dominance deviation (D), and the epistatic deviation (I): 
and

$$
\mathrm{Gi}=\mathrm{Ai}+\mathrm{Di}+\mathrm{Ii}
$$

$$
\mathrm{Pi}=\mathrm{Ai}+\mathrm{Di}+\mathrm{Ii}+\mathrm{Ei}+(\mathrm{A} \mathrm{X} \mathrm{E}) \mathbf{i}+(\mathrm{D} \mathrm{X} \mathrm{E}) \mathbf{i}+(\mathrm{I} \mathrm{X} \mathrm{E}) \mathbf{i}+\mathrm{ei}
$$

The additive genetic value (A) is the sum of the effects of the genes across all the loci influencing the trait. In an analysis of variance sense, the additive gene effect is the main effect of the genes on the phenotype. Dominance deviation (D) occurs when the two alleles within a locus are not of equivalent influence. At a locus, a gene may be recessive and not be manifested in the phenotype unless paired with another recessive gene at the same locus. Dominant genes will often, but not always, neutralize the effects of recessive genes, depending on whether the dominant gene exerts complete, over-, or partial dominance. Dominance effects cause the genotype to deviate from its expected value based on the additive genetic effect. Epistatic interaction deviation (I) refers to the interaction of alleles between loci. Epistatic interaction deviation represents the remaining influence of genetic variation on phenotypic variation after additive genetic and dominance effects have been removed, and are typically small. Collectively, dominance deviation and epistatic interaction deviation are known as nonadditive genetic effects, the "nonadditive" a lexical gift from the analysis of variance signifying their interactional nature.

Because each of the genetic and environmental influences has been expressed as a deviation score, the model is revised to express the contribution of each of the sources to the variance in the phenotype. First taking the genetic effects over all $N$ individuals in the population, we find by the rules for the variance of an unweighted composite:

$$
\begin{gathered}
\mathrm{VG}=\mathrm{VA}+\mathrm{VD}+\mathrm{VI}+2 \mathrm{Cov}(\mathrm{A}, \mathrm{D})+2 \operatorname{Cov}(\mathrm{D}, \mathrm{I}) \\
+2 \operatorname{Cov}(\mathrm{I}, \mathrm{A})+\mathrm{VA} \text { X D }+\mathrm{VD} \text { X I }+\mathrm{VI} \text { X A }
\end{gathered}
$$

This model for the total genetic variance may be greatly simplified. Additive, dominance, and epistatic effects may be assumed to be uncorrelated (Kempthorne, 1957) provides a rather complex explanation for this assumption). The three interaction terms may also be removed from the equation. Although interactions among the three genetic effects do occur, their identification, especially with human data, is difficult, if not impossible, with the methods currently available. In addition, their contribution to the total phenotypic variance can be expected to be quite small, relative to the other variance components. Typically, epistatic interaction variance is left confounded with 
dominance variance, for the detection of the unique contribution of each in humans is extraordinarily difficult. Therefore, the model for the total genetic variance is:

$$
\mathrm{VG}=\mathrm{VA}+\mathrm{VD}
$$

If the environmental deviation score is incorporated into the variance partitioning, the total variance in a phenotype over all $N$ members of the population is:

$$
\begin{aligned}
\mathrm{VP}= & \mathrm{VA}+\mathrm{VD}+\mathrm{VE}+2 \operatorname{Cov}(\mathrm{A}, \mathrm{E}) \\
& +2 \operatorname{Cov}(\mathrm{D}, \mathrm{E})+\mathrm{VA} X \mathrm{X}+\mathrm{VD} \mathrm{X} \mathrm{E}+\mathrm{Ve}
\end{aligned}
$$

According to the model, the total variance in a phenotype is a function of the variance in both additive and nonadditive genetic effects, variance in the environment, and the variance due to the correlation and interaction between the various genetic and environmental effects. As in any correlation, where certain values of one variable tend to occur in concert with certain values of another variable, a significant genotype-environment correlation represents the nonrandom distribution of the values of one variable (genotype) across the values of another variable (environment). Consequently, different phenotypes are selectively exposed to environmental experiences based upon their differing genetic propensities. As one example, genotype-environment correlation may be of importance when young adults differing in intelligence select different career paths. If the more-intelligent young adults select more intellectually demanding occupations, then a positive association is found between genotype and environment. But genotype-environment correlation can be negative as well, a situation that could occur, for instance, when young adults of lower intelligence are coerced by their parents to pursue the same intellectually demanding occupations as the more intelligent young adults. The foregoing examples imply a linear correlation between genotypes-environments; genotype-environment correlations can also be nonlinear. Cattell's (1982) idea of "coercion to the biosocial mean” is an example of a nonlinear genotype-environment correlation, in which the correlation tends to be negative for individuals at high and low levels of a trait, and positive in-between the two levels. Supposedly, society attempts to moderate the "extreme" behavior of individuals by coercing them to behave more moderately; for example, too much or too little aggression is usually discouraged or even punished. Of course, there must be a significant genetic component to the trait.

It should be noted that traits differ in the extent to which additive genetic and 
nonadditive genetic effects are both influential in individual differences. In the case where the two genetic sources of variance have not been differentiated or only additive genetic variance is of concern, the total genetic variance can be represented as before, VG. In the situation where a trait is influenced by both additive and nonadditive genetic variance, we ask whether it is possible for the two components of variance to differentially correlate with the environment; the situation where $\operatorname{Cov}(A, E)$ is significant but $\operatorname{Cov}(D, E)$ is not. For example, where directional selection occurs, only $\operatorname{Cov}(A, E)$ is likely to be significant; where stabilizing selection occurs, only $\operatorname{Cov}(\mathrm{D}, \mathrm{E})$ is likely to be significant. Generally, if directional or stabilizing selection is not of particular concern, genotypeenvironment can be neutrally written as "Cov(G,E).”

Therefore, the total variance in a phenotype is expressed as:

$$
V P=V G+V E+2 \operatorname{Cov}(G, E)+V G X E+V e
$$

In the model, GXE is considered simply as another source of variance contributing to individual differences on a trait, exerting influence above and beyond the influence of genetic and environmental main effects.

One difficulty with accepting GXE as an important influence on human behavior is the virtual absence of evidence of its significance; on the contrary, evidence is readily available that GXE is generally not significant. For example, three books report the exhaustive attempts that have been made to detect GXE in data from the Colorado Adoption Project (DeFries, Plomin, \& Fulker, 1994; Plomin \& DeFries, 1985; Plomin, DeFries \& Fulker, 1988), a longitudinal adoption study examining the development of a number of cognitive ability and personality variables from infancy through young adulthood in a sample that includes adopted children and their adoptive and biological families. Of the hundreds evaluated, the number of significant GXE does not exceed the nominal Type I error rate of 5\%.

A number of methods have been proposed to detect GXE. We illustrate the application of two methods to work on environment-related variables from the Swedish Adoption/Twin Study of Aging (Hershberger, Lichtenstein, \& Knox, 1994), a longitudinal study of adult reared-together and reared-apart monozygotic and dizygotic twins. In both methods, data from only reared-apart monozygotic twins (MZA) are used.

The first method, proposed by Jinks and Fulker (1970), involves correlating the means of MZA pairs with the corresponding absolute intrapair differences. Applying this test to MZAs detects genetic effects on sensitivity to the environment that are correlated with genetic effects on average trait value. The variables examined for GXE were the 10 scales from the Work Environment 
Scale (WES) (Moos, 1981): Work involvement, peer cohesion, supervisor support, work autonomy, task orientation, pressure, role clarity, control, innovation, and physical comfort. None of the correlations was significant, thus implying that GXE was not present in these data.

In the second method of detecting GXE, hierarchical regression is used to remove joint effects of genotype and environment and then to assess their interaction in predicting a twin's report of the work environment (Plomin, DeFries, \& Loehlin, 1977). In addition to the 10 scales of the WES, three "objective" environmental variables are included in the analysis: (1) occupation type (whose four categories range from "unskilled" to "professional”), (2) level of education required for occupation, and (3) the amount of physical labor involved in the occupation. The method assumes that the response of one of the twins within each MZA pair serves as an estimate of the co-twin's genotype. In the first step of the hierarchical regression, one twin's response to a scale from the WES is regressed onto the co-twin's response in order to assess the significance of genetic effects. In the second step, one of the three objective work environment variables is included in the model in order to assess the significance of environmental effects. In the third and last step, the product between the WES and the work environment is added to the model in order to assess the significance of GXE. Because there are 10 scales from the WES and three work environment variables, 30 hierarchical regression analyses were conducted. Of these 30, only three were significant-approximately what would be expected using a nominal Type I error rate of $5 \%$. Thus, in these data, no evidence was found for GXE.

Also suggestive of GXE's dispensability is the finding that even if GXE is significant, failing to specify it as a parameter in the quantitative genetic model does not significantly affect the values of the model's other parameters (e.g., the heritability does not change) (Molenaar \& Boomsma, 1987). In contrast, if $\operatorname{Cov}(\mathrm{G}, \mathrm{E})$ is significant but not specified, the other parameters become biased: If $\operatorname{Cov}(\mathrm{G}, \mathrm{E})$ is positive, the estimated heritability is too high; if $\operatorname{Cov}(\mathrm{G}, \mathrm{E})$ is negative, the estimated heritability is too low (Hershberger, 1991).

A statistical red herring is occasionally introduced to avert attention away from the theoretical and statistical shortcomings of GXE. GXE apologists emphasize the exceptional power requirements for detecting significant interactions (e.g., Wahlsten, 1990). So be it. It is the responsibility of those who want to detect interactions to design more powerful studies. Detecting significant $\operatorname{Cov}(\mathrm{G}, \mathrm{E})$ also requires exceptional power (e.g., Eaves, Last, Martin, \& Junks, 1977), but as indicated below, this does not seem to have seriously affected our ability to find $\operatorname{Cov}(G, E)$ when we look for it. A statistical anomaly of GXE that is troubling is the possibility of finding significant GXE effects in 
the absence of significant genetic and environmental main effects. In contrast, for $\operatorname{Cov}(\mathrm{G}, \mathrm{E})$ to be significant, both genetic and environmental main effects must be significant. In natural environments, it is extremely unusual to find an animal or human phenotype that does not have significant genetic and environment main effects of some type (Falconer, 1981). In fact, significant GXE without significant genetic and environmental effects is a spurious result of exposing organisms to unnatural environments, environments they would never encounter without the assistance of researchers.

From an evolutionary perspective, the ubiquitous GXEs envisioned by Gottlieb are not expected. Additive genes have their effects on a wide range of normal genetic backgrounds and across a wide range of normal environments. The evolutionary logic of such genes is that when a trait such as intelligence is under directional selection, there would be selection for genes that provide a general positive effect on the trait that is more or less independent of genetic background and a wide range of normal environmental rearing conditions. For example, the genes for intelligence are predominantly additive (e.g., Plomin, 2003). Given that intelligence (or increased lung capacity or increased oxygen efficiency) is a valuable trait for the organism, genes that contributed to intelligence in one commonly encountered environment but lowered intelligence in another commonly encountered environment would be at a disadvantage. The presence of complex, unpredictable, and idiosyncratic interactions envisioned in DST would make it very difficult for natural selection to construct complex adaptations. Complex adaptations require multiple, smoothly meshing genes that produce qualitatively similar phenotypes throughout the entire range of environments encountered in the EEA. This does not imply that there are no interactions at all or that individual differences would be absolutely preserved over a wide range of normal environments (Turkheimer, Goldsmith, \& Gottesman, 1995). It does mean that such interactions are not expected to disrupt the design plan of complex adaptations.

Another reason why a major influence of GXE is inconsistent with evolutionary theory is suggested by the ubiquitous significance of $\operatorname{Cov}(G, E)$. This is because $\operatorname{Cov}(\mathrm{G}, \mathrm{E})$ and $\mathrm{GXE}$ are fundamentally incompatible processes if one accepts that the results of natural selection are organisms adapted to their environments. Recall that significant $\operatorname{Cov}(\mathrm{G}, \mathrm{E})$ implies that genotypes are systematically matched to environments. This is exactly what would be expected under natural selection. On the other hand, for GXE to be significant, a range of genotypes must be found within each environment. This is highly unlikely, if not impossible, under natural selection. Natural selection severely reduces the variety of genotypes found within any environment; greater reductions result in higher $\operatorname{Cov}(G, E)$. Natural selection never gives GXE much of a chance. 
Evidence for the importance of $\operatorname{Cov}(\mathrm{G}, \mathrm{E})$ for many human phenotypes is not difficult to find; for example, in contrast to $G X E, \operatorname{Cov}(G, E)$ has been found for many of the cognitive ability and personality variables measured in the Colorado Adoption Project. As is the case for GXE, a number of methods have been proposed for detecting $\operatorname{Cov}(\mathrm{G}, \mathrm{E})$. We will describe one such method and its application to data from the Colorado Adoption Project. This method is designed to detect "reactive" $\operatorname{Cov}(\mathrm{G}, \mathrm{E})$, in which individuals evoke experiences that derive from the reactions of others to the individual's genetically influenced behavior. To compute $\operatorname{Cov}(\mathrm{G}, \mathrm{E})$, measures of genotypes and environments are required. In the Colorado Adoption Project, the genotype of adopted children can be indexed by scores from their biological parents, and the environment of adopted children can be estimated using any measure of the adoptive home environment or characteristics of the adoptive parents (Plomin et al., 1977). If adoptive parents react to their adopted children on the basis of genetic differences among the children, correlations between the scores of the biological parents and environmental measure should be significant. In the absence of selective placement, this method will detect $\operatorname{Cov}(G, E)$ when there is a heritable relationship between the phenotype of biological parents and their adopted-away children and when there is a relationship between the environmental measure and the phenotype of adopted children. The correlation computed under this method is consistent with the definition of $\operatorname{Cov}(\mathrm{G}, \mathrm{E})$ : Genetic differences among children are correlated with differences among their environments.

From the Colorado Adoption Project data, a set comprising 15 birth mother characteristics was correlated with a set comprised of 10 scales from the Family Environment Scale (Moos \& Moos, 1981) when adopted children were 1, 3, 5, $7,9,10$, and 11 years of age. This canonical $\operatorname{Cov}(\mathrm{G}, \mathrm{E})$ was significant at each age, increasing from its lowest value of .32 at 1 year of age to its highest value of .59 at 11 years of age.

Those theorists who insist on the importance of GXE for human behavior are motivated by an idée fixe: If only we could place individuals within their optimal environments, individual differences would disappear. Disappearing with them would be a multitude of undesirable phenotypes: At last, the uneducable would become educable; the poor, wealthy; and the emotionally disturbed, well. GXE is not the first time interactions have been used to satisfy the utopian fantasies of social scientists. Aptitude X treatment effects were once hypothesized to be of the greatest importance in education (Cronbach \& Snow, 1977). According to the proponents of this interaction, finding optimal methods of instruction for each student leads to the eradication of individual differences in learning. However, several decades of nonreplicable findings have convinced most researchers otherwise. After birth, the idea of aptitude X treatment effects 
died from a failure to thrive in a research setting. We predict that GXE will meet a similar fate. We live in a world primarily of main effects, with a few true interactions complicating the picture. And given enough time, these interactions will themselves evolve into main effects. These are the logical consequences of natural selection.

One is struck in reading the debate between Gottlieb and his critics that both sides pay homage to the idea that DST is an accurate picture of the real nature of developing systems. For example, Turkheimer, Goldsmith, and Gottesman (1995) note that "ultimately the relationship between genotype and phenotype cannot possibly be linear" (p. 148). Scarr (1995) states that "we do not fully understand the complex, nonlinear web of mechanisms involved in producing these outcomes" (p. 155). Behavior genetic methods are therefore seen as useful simplifications of a complex reality that can only be captured by probabilistic, nonlinear models.

We suggest the reverse: Models stressing additive genes and additive environmental effects reflect the fundamental reality discussed above. The genes that are most easily incorporated into many complex adaptations are selected (a) because they result in reliably developing phenotypes across a wide range of environments, (b) because additive genes are most easily incorporated into complex adaptations due to the fact that such genes have predictable effects on the phenotype independent of genetic background, and (c) because naturally occurring environments are often structured to result in additive increments to the phenotype for genetically normal people.

In the case of personality systems, there is reason to expect that nonadditive genetic variation will be more common (MacDonald, 1998; Segal \& MacDonald, 1998; see Ch. 8, this volume). This is because personality systems function to deal with conflicting demands of the environment and because personality systems are likely to be shaped by stabilizing selection rather than directional selection. Personality systems are profoundly interactive at the physiological level, with mutual inhibitory linkages among systems (Fox, 1994; see MacDonald, Ch. 8, this volume): Events that trigger behavioral withdrawal and fear also trigger inhibition of other personality systems underlying behavioral approach and positive emotions. As a result, genes that strengthen an animal's fear system may work by more effectively inhibiting behavioral approach mechanisms and therefore have different effects depending on the strength of the organism's approach systems. The result is that unlike the case for intelligence, there are relatively high levels of nonadditive genetic variation associated with personality systems (Segal \& MacDonald, 1998).

In the case of personality systems, it is likely that stabilizing selection (i.e., selection against extremes) rather than directional selection occurred. Individuals who are extremely high or extremely low on particular traits would 
appear to be at a disadvantage, but there is a broad range of genetic variation in the middle of the distribution underlying a range of viable strategies. Indeed, extremes on personality distributions are associated with psychopathology. Extreme sensation seeking, for example, would tend to result in dangerous risk taking and impulsivity, while individuals who are extremely low on these appetitive traits would lack motivation to pursue goals related to the accumulation of sexual and personal resources. Extremes in either direction would appear to be maladaptive. On the other hand, the wide diversity of intermediate individuals resulting both from genetic variation and developmental plasticity would be able to occupy different social roles and have differing balances between caution and impulsivity.

Gottlieb makes much of findings of average effects on IQ in adoption studies (e.g., Capron \& Duyme, 1989; Scarr \& Weinberg, 1983). Both Gottlieb (1995) and Bjorklund and Pellegrini (2002) ignore the results of follow-up studies that indicate a much-attenuated average effect as adopted children approach adulthood (Weinberg, Scarr, \& Waldman, 1992; see also Bouchard, 1993). Positive effects of adoption are likely when children are adopted out of abusive environments (e.g., Dennis, 1973); but such results imply that in general and averaged over all genotypes sampled in the population, the difference in environments has a consistent, unidirectional effect on the adopted children. This additive environmental effect is a common finding in animal studies and makes excellent evolutionary sense: For example, it is well known in ecology that environments vary from marginal to excellent. These gradients in quality (relative lack of nutrients, poor climate, high risk of predation) imply that there would be average effects on a wide range of characteristics depending on environmental quality. In IQ research, the Flynn effect of increasing IQ scores over historical time has been attributed to better nutrition (Lynn, 1996). Better nutrition and other improvements in the modern world have resulted in large increases in height and earlier ages of menarche. The general positive effect of enriched versus deprived environments is central to the reaction range concept defended by Turkheimer, Goldsmith, and Gottesman (1995) and, despite his misgivings, is apparent in Gottlieb's (1995, p. 135) own presentation. This implies that the effects of the environment are far from capricious or unpredictable as implied in Gottlieb's description of his model. If it were, parents could not reasonably suppose that feeding the child a diet with an adequate amount of protein would be better than no protein at all. These findings also show that genotype-environment interactions are not the main story in development.

We conclude that there is no theoretical problem with the standard behavioral genetic practice of partitioning additive and nonadditive genetic variance and 
shared and unshared environmental variance. Additive genetic and environmental effects make excellent evolutionary sense for systems such as intelligence that are beneficial for organisms in the entire gamut of environments normally encountered by the species. However, the peculiar nature of personality systems as responsive to a variety of often incompatible environmental demands and the complex interaction among personality systems at the physiological level means that nonadditive genetic variance (but not GXE interaction) plays an important role.

A major difference between evolutionary approaches and behavior genetics is that the former attempts to "carve nature at its joints" - that is, it attempts to discover the actual systems that have been under natural selection and serve adaptive functions. Behavior geneticists, on the other hand, have not limited themselves to finding the contributions of genetic and environmental sources of variation in naturally evolved systems, but have applied their methods to any trait that shows variation. For example, behavior genetics research shows that the propensity for divorce is heritable (McGue \& Lykken, 1992; Turkheimer Lovett, Robinette, \& Gottesman, 1992). Evolutionary psychology can undoubtedly shed some light on divorce. For example, infidelity is the leading cause of divorce (Betzig, 1989), a result expected because spousal infidelity imposes costs on both partners. However, the genetic variation for divorce is not only likely to be "radically polygenic" (Turkheimer, Goldsmith, \& Gottesman, 1995, p. 152), it is likely to be radically polysystemic, spread among a wide range of evolved systems: People with a wide range of differences on personality that make them difficult to live with (e.g., high on neuroticism/emotional reactivity), prone to philandering (high on behavioral approach), low sex drive (low on behavioral approach), unrewarding as a mate (low on nurturance/love), and a poor provider (low on conscientiousness and intelligence) would all be more likely to get divorced. People also get divorced because their mates gain weight, lose hair, or are infertile. As a result, the genetic variation for divorce is spread among a wide range of evolved systems, so that behavior genetic analysis of this trait is of little interest to an evolutionist. To make matters worse, the likelihood of divorce also depends on the legal climate: Divorce was essentially unheard of until about 50 years ago in Western cultures, and provisions for finding fault and dividing assets also affect divorce rates. However, heritability studies of divorce have a certain practical interest; for example, it is relevant to clinical practice to know the heritability of traits in normally occurring environments (Scarr, 1995), although, of course, even a high heritability would not prevent an inventive clinician from designing interventions that could change the probability of divorce or the sequelae of divorce, even if such environments were never encountered in the EEA.

The behavior genetic analysis of evolved systems is of considerable interest. 
The most important of the evolved systems are those related to general intelligence and the major personality systems (Chiappe \& MacDonald, 2005; see MacDonald, Ch. 8, this volume). Although evolutionary psychologists have suggested that genetic variation in evolved systems is mere noise (Tooby \& Cosmides, 1990), there is good reason to suppose that genetic variation in evolved systems is adaptive-that genetic variation promotes occupying different niches and that people possess adaptations that allow them to assess phenotypic variation of themselves and others in order to advance their interests (MacDonald, 1998). The general theory for understanding the methods by which individuals interact with the phenotypic and genotypic resource environment represented by human diversity may be termed intraspecific diversity theory, that is, the theory of the assessment and manipulation of within-species diversity as a resource environment. The reality is that people are acutely interested in the phenotypic variation in themselves and others. Different qualities are important in different relationships-for example, honesty, intelligence, and conscientiousness in many job situations, and affection in close romantic relationships. If genetic variation were mere noise, we would not be so deeply interested in this variation.

Within an evolutionary systems perspective, environmental influences are conceptualized as involving specific types of stimulation directed at particular evolved systems. Thus, environmental influences affecting the conscientiousness system would be expected to be events related to possible threats to personal safety or long-term goals, while environmental influences related to nurturance/love would be expected to involve warmth and affection that typically occur in close family relationships.

\section{Developmental Plasticity}

The first author's 1988 introductory chapter accepted the traditional notion of developmental plasticity rooted in the reaction range idea (Gottesman \& Shields, 1982) as compatible with an evolutionary perspective (see also Bjorklund \& Pellegrini, 2002). Evolutionary psychologists have problematized the traditional notion of developmental plasticity. Tooby and Cosmides (1992) claim that "plasticity" can be retained only if it guides behavior into "an infinitesimally small adaptive space” (p. 101). Such plasticity is really only apparent, the result of large numbers of conditional "if-then" mechanisms 
responsive to recurrent contingencies in our evolutionary past.

An example that fits this analysis is the life history model of Belsky, Steinberg, and Draper (1991), in which resource scarcity results in a pattern of exploitative interpersonal relationships and precious sexuality, whereas resource security results in trusting personal relationships and delayed sexual maturation. Another type of developmental plasticity that can be accommodated by this sort of model is the "fine-tuning" of the nervous system by synaptic pruning in the presence of a highly reliable source of environmental information that can guide the elimination process (see above). Fine-tuning is also central to Geary and Huffman's (2002) proposal on soft modules as underlying play and exploration. Fairbanks (2000) reviews evidence indicating that play functions to prune synapses in the cerebellum and elsewhere in the brain.

Despite surface appearances, there isn't any logical difference between the traditional idea of developmental plasticity based on a reaction range notion and the proposal of Tooby and Cosmides (1992). If one construes a normal reaction range for a trait as the EEE, then any point in the range can be considered as responsive to recurrent environmental cues. From this perspective, the reaction range from deprived to enriched environments for a particular trait represents a continuum of if-then relationships defining the plasticity for the trait. Of course, this way of thinking about plasticity renders Tooby and Cosmides's claim for an infinitesimally small adaptive space true by definition. It also seems odd to think of reaction ranges as composed of large numbers of adaptations, each aimed at some particular infinitesimally small range, as opposed to, say, one adaptation that responds predictably to a range of environments - a fairly wide range in the case of the effects of nutritional variation on stature. Such a notion of plasticity is compatible with the quantitative models of behavior genetics.

The theory of plasticity proposed by Tooby and Cosmides does not address examples where plasticity is blind, that is, examples where environmental events that are not part of an organism's EEA are able to influence the phenotype. But there are myriad examples showing that people and other organisms are able to respond adaptively to environmental novelty and uncertainty. As discussed above, learning and general intelligence function exactly this way, and learning has effects on the brain. For example, Greenough and Black (1992) provide evidence for effects on the brain of unpredictable environmental influences, as when learning results in changes in synaptic organization. Similarly, humanreared chimpanzees show superior symbol-learning ability and social learning compared with nonhuman-reared chimpanzees (Tomasello, 1999). Since being reared by humans is not part of the chimpanzee's EEA, this example suggests that plasticity carries with it the possibility that natural capabilities may be enhanced in environments that were not characteristic of the animal's EEA.

Tooby and Cosmides's theory implies that events outside those recurrent in 
the EEA would tend to produce pathology, and there certainly are examples of such events. Extreme abuse and lack of stimulation or social contact come to mind. However, in addition to mechanisms of learning and general intelligence, there are a variety of other mechanisms for dealing with uncertainty. Although recurrent and expected environments are of fundamental importance to an evolutionary account, organisms have evolved mechanisms of plasticity that allow accommodation to at least some genetic mutations and to at least some extreme environments that were not recurrent in the EEA (West-Eberhard, 1989, 2003). The changes following a mutation that shortened the front legs of a goat are a classic example. This mutation resulted in a large number of compensatory changes in the animal's skeletal and muscular systems, resulting from the fact that the animal now walked on its rear legs. This ability to compensate for unexpected developmental disruptions is a powerful example of plasticity.

The importance of domain-general psychological mechanisms for human adaptation implies a high level of human plasticity indeed. For example, as a result of their high level of cognitive abilities-prototypically human general intelligence-humans are able to create cultural mechanisms, ranging from social controls and ideologies that regulate sexual behavior to medical technology able to cure genetic diseases (Laland, Odling-Smee, \& Feldman, 2000; Li, 2003; MacDonald, 1988b, 1995b). The claim that human adaptations respond to an infinitesimally small adaptive space implies that humans would not be able to change their sexual behavior even after contraception and the availability of safe abortion dramatically lowered the cost of sex, especially for women. However, there is a great deal of evidence that sexual behavior has changed dramatically since the advent of safe and reliable contraception and abortion (e.g., Furstenberg, 1991).

Plasticity is also implicated in traits produced by environmental induction as a result of extreme or unusual environmental influences, as in genetic assimilation and similar phenomena (West-Eberhard, 2003, pp. 151-154). For example, in the Baldwin effect, there is a phenotypic response to variable or extreme environments made possible by plasticity. Genetic mechanisms then accommodate to the new phenotypic change via natural selection on "variation in the regulation, form or side effects of the novel trait" (West-Eberhard, 2003, p. 140). In other words, genetic changes accommodate to the new phenotype, for example, by making it work more smoothly; but the original alteration of the phenotype occurs as the result of plasticity. As a result, the new trait becomes heritable. A possible example is dwarfism in elephants, caused originally by inadequate nutrition on islands affecting the phenotype via developmental plasticity. The inadequate nutrition causes stunting, followed by selection on previously existing genetic variation. The trait then become genetically 
consolidated with the result that better nutritional conditions do not result in the return of the large phenotype.

Indeed, according to West-Eberhard (2003), developmental plasticity is central to the entire evolutionary process. Evolution begins with a recurrent developmental change brought about either by a mutation or (more commonly) by developmental plasticity interacting with environmental events. Selection then consolidates the trait by modifying genes influencing the regulation of the trait. An example of this would be where learning particular contingencies is shaped by natural selection: If there is genetic variation for the ability to learn a particular contingency, natural selection may act to strengthen the ability to learn this contingency. Examples where natural selection has shaped learning are central to evolutionary accounts of learning, as in taste aversion learning among rats (see above), but the central role of plasticity in initiating the changes wrought by natural selection is typically left out of the accounts produced by evolutionary psychologists.

\section{Human Growth as an Example of Plasticity}

Variation in nutrition is attractive for studying plasticity because nutritional variation is a recurrent environmental feature and thus likely to result in adaptations designed to cope with it. The effects of malnourishment are also well studied and easily controlled for genetic factors, quite unlike the situation with many other psychological systems. In general, it is reasonable to suppose that environmental influences are system-specific, for example, that the fear system is influenced by traumatic events and the affectional system by warmth and affection (Segal \& MacDonald, 1998).

Researchers in the area of the plasticity of human growth have found irreversible changes in stature and other anthropomorphic measures in response to variation in caloric intake and other components of nutrition during development (Bogin, 2001; Mascie-Taylor \& Bogin, 1995; Roberts, 1995; Schell, 1995; Stoch, Smythe, Moodie, \& Bradshaw, 1981). For example, malnourishment before birth has a series of long-term medical consequences, such as increased likelihood of Type 2 diabetes, even when the children achieve normal weight and height as a result of high-caloric intake during childhood (Forsén et al., 2000). 
However, the brain retains "preferential access to nutrients even in conditions of semi-starvation" (Stevens, 1998, p. 257), an indication of the importance of the brain for later functioning. Research on environmental insults to the brain during development supports the generalization that periods of rapid change are most open to environmental influence (Morgan \& Gibson, 1991), the classic sensitive-period notion deriving from ethology. A great many influences that are deleterious to the developing brain have little or no effect on the adult brain, and in general, the effects of early experience become increasingly irreversible with age (Shonkoff \& Phillips, 2000). Animal studies indicate that severely malnourished brains never recover fully, even when subjected to intensive nutritional rehabilitation in the postweaning period. Catch-up growth does occur in children, but best results are achieved if rehabilitation is begun during the period when cell division is still occurring and continuing through the period of myelination and dendritic arborization (Morgan \& Gibson, 1991). Indeed, Morgan and Gibson describe the second trimester as a " "critical period' for the formation of cortical neurons" (p. 98). For the critically important variable of intelligence, nutritional rehabilitation of severely malnourished children treated before 2 years of age resulted in the children attaining American norms for intelligence, but children rehabilitated after this age remained below the norms (Lien, Meyer, \& Winick, 1977; Winick, Meyer, \& Harris, 1975).

As indicated above, the model of West-Eberhard for the evolution of dwarfism in elephants suggests that cultures subjected to a diet deficient in protein and calories over many generations would develop a hereditary tendency toward small stature, low energy output, and low intelligence. Bogin (2001) interprets his work comparing Mayans in the United States and in Guatemala as indicating that the relatively enriched environment of the United States resulted in the Mayan children approaching U.S. norms in one generation, results suggesting that natural selection had not effected a genetic tendency toward the low-energy phenotype. However, although there were large gains in both height and weight during childhood compared with Guatemalan norms, at age 15, the children were much closer to U.S. norms for weight than for height. At age 15, height remained intermediate between U.S. norms and Guatemalan norms, suggesting that developmental plasticity is more important for weight than height and suggesting at the least that more than one generation would be required to attain U.S. norms in height.

West-Eberhard (2003) argues for the transmission of environmental influences between generations. For example, in migratory locusts, effects of maternal crowding on adult phenotypes accumulate over four generations before leading to a migratory phenotype. Such cumulative, between-generation effects may be important for humans in the area of nutrition. For example, Asian 
immigrants to Scotland increased in height every generation since arrival (Shams \& Williams, 1997). In general, degree of plasticity "correlates with degree of environmental variation in the parameter to which plasticity responds" (West-Eberhard, 2003, p. 179), and there is little doubt that variation in nutritional regime has been common for humans over evolutionary time. The suggestion is that humans are adapted to respond quickly to improvements in nutrition but that several generations may be required to maximize traits such as height within a particular nutritional regime. Of course, this generalization is compatible with average racial/ethnic differences in the maximum attainable within any given nutritional regime.

Bogin's (2001) finding that the height of Mayan children in the United States increasingly resembles the height of Guatemalan Mayans with age may well reflect the general tendency for heritability for a wide range of traits to increase with age. For example, the heritability of the critical trait of general intelligence ranges from 0.2 in infancy to 0.4 in childhood to 0.6 in adulthood (McClearn et al., 1997; McGue, Bouchard, Iacono, \& Lykken, 1993). This implies that environmental influences on individual differences in intelligence become less important as people age. It is a remarkable fact that unrelated children living in the same household become less and less like each other as they approach adulthood, and by the time they reach adulthood, their correlation for IQ is zero (Rowe, 1994; Scarr \& Weinberg, 1983).

\section{Human Life History Characteristics: The Most Important Single Fact About Human Development Is the Development of the Adult Brain}

A major point of the preceding is the central importance of domain-general psychological mechanisms of general intelligence for thinking about human adaptation. Developmental increases in speed of processing and of mechanisms underlying increases in general intelligence are the central story, perhaps the central story of children's cognitive development. Moreover, there is excellent evidence that general intelligence is an adaptation underlying the ability of humans to create novel solutions to ancient problems of survival and reproduction. There is little doubt that general intelligence underlies the human 
ability to create the extraordinary culture characteristic of the last 50,000 years of human evolution.

This suggests that the development of the human brain is also the central fact of human life history theory, the theory of how organisms allocate energy toward growth, maintenance, reproduction, and rearing offspring (Allman, 1999). According to Charnov's (2001) theory, what needs explaining in life history is the length of the prereproductive period. Among mammals, there is a relatively constant relationship between life span and age of first reproduction. While animals benefit from a longer prereproductive period by increasing in size and obtaining other resources that will benefit future reproductive ability (e.g., a more efficient brain), a lengthy prereproductive period is enormously costly because it increases the cost of parenting and increases the changes of mortality prior to reproduction.

One theory that has attempted to explain the prolonged human prereproductive period is that children benefit by being able to learn information and hone abilities that are critical for successful adult functioning (e.g. Bjorklund \& Pelligrini, 2002; Flinn, Ch. 3, this volume; Geary, Ch. 4, this volume; Kaplan, Hill, Lancaster, \& Hurtado, 2000; MacDonald, 1997a). Learning accounts are called into question by several considerations (see Bogin, 2001, p. 103; Deaner, Barton, \& van Schaik, 2003). If learning was so important to human development as to result in the enormous costs of a prolonged preadulthood, it is surprising that children's cognitive and learning abilities are so limited and inefficient compared with adults', at least until late adolescence. Indeed, Kail (1991) found that the average performance of 8- to 10-year-old children for response times on a wide range of intellectual tasks is typically 5 to 6 standard deviation units below the mean for young adults; even 12- and 13year-olds perform more than a full standard deviation below the young adult mean. Moreover, Blurton Jones and Marlowe (2002) found no evidence that children require prolonged periods to learn the skills of hunting and gathering. Bogin (2001, p. 103) also notes that the learning hypothesis can't account for the alternating fast and slow growth pattern characteristic of humans, and it can't explain the length of the prereproductive period in humans.

The relatively trivial benefits accruing from "the adaptive uses of immaturity" (Bjorklund \& Pelligrini, 2002, p. 203) also seem insufficient to account for such an enormously costly childhood. Indeed, the principle example of adaptive immaturity, children's tendency to overestimate their cognitive ability, would be obviated if children's cognitive ability were more sophisticated to begin with. Finally, the finding of increased genetic influence with age on a wide variety of measures of individual differences (see above) suggests that many early environmental influences wash out prior to adulthood. 
An alternate set of hypotheses - all mutually compatible-center on the idea that the prolonged prereproductive period of human development is needed to produce the extraordinarily powerful human brain because of physiological constraints on brain development (see Deaner et al., 2003). Childhood is so lengthy because mother nature simply cannot construct the human brain in a shorter period. Such an extended childhood is extremely costly, but it can evolve because it has huge delayed benefits. In particular, the advanced cognitive abilities of the adult brain reduce adult mortality due to predation or food shortages and eventually, with Homo erectus, produce cultural shifts that have resulted in the complete ecological dominance of humans throughout the world. Such a brain would also be useful in navigating the social world of competing humans (see Flinn, Ch. 3, this volume; Geary, Ch. 4, this volume; Oller \& Griebel, Ch. 5, this volume).

Any hypothesis for explaining the prolonged developmental period of children must take account of the fact that brain development is the driving force of human development and by far the most important contributor to human life history characteristics. Newborns use $87 \%$ of their resting metabolic rate for brain growth and functioning, a figure that declines to $44 \%$ by age 5 and $25 \%$ in adulthood (Bogin, 2000). These percentages are more than twice the levels for chimpanzees. Because of their relatively large brains, humans must have access to a diet that is rich in energy (Leonard \& Robertson, 1994). As noted above, the brain is relatively buffered from nutritional deprivation compared to other systems (Stevens, 1998). According to Gibson (1991; see also Deaner et al., 2003), the dependence of this enormously costly organ on adequate resources favors extended developmental periods, because only by extending development can adequate nutrition be obtained. A rapidly developing large brain would be more susceptible to temporary nutritional deficits, while the slowly developing myelination of the human brain affords a prolonged period during which nutritional rehabilitation is possible (Morgan \& Gibson, 1991). This fits well with evidence indicating that the normal response of humans to lowered levels of nutrition or other stressors is to delay development, while better nutrition results in earlier puberty (MacDonald, 1997b, 1999).

Another possible physiological limit is described by McKinney (2000), who attributes the unique features of human brain development to a predisplacement process in which a larger proportion of embryonic neuron stem cells produce a larger, slow-growing brain. This process involves terminal extension or overdevelopment-additions to the primate brain, rather than neotenous processes in which adult forms retain juvenile characteristics (e.g., Langer, 2000; McKinney, 2000). Because of inherent limits on mitotic cell division processes for nerve cells, terminal extension results in a very long developmental period required for full brain development. Postnatal brain 
development is quite slow, but body growth is also slow until the adolescent growth spurt, resulting in an energetically efficient body sustaining a slowgrowing brain. Dendritic growth and myelination (critical to efficient nerve transmission) continue well into the adolescent period.

In general, compared with other primates, peak rates of neurogenesis, dendritogenesis (and pruning), synaptogenesis, and myelination occur later in modern humans, and each process is itself extended (Gibson, 1991). Significantly, myelination in the neocortex and especially the prefrontal cortex, the seat of working memory and general intelligence, are the last areas to be completed. The human prefrontal cortex is more than twice the size of an anthropoid ape corrected for body size-an indication of the importance of the domain-general processes underlying intelligence in human evolution (see above; see also Geary, Ch. 4, this volume). Among primates, size of the neocortex is significantly associated with life span, data consistent with the hypothesis that decreased adult mortality mediated by human intelligence is a driving force of human evolution (Deaner et al., 2003).

Hawkes, O’Connell, and Blurton Jones (2002) argue against the brain development hypothesis by pointing to the separation by 1 million years between the evolution of human life history characteristics (attributed to Homo erectus), and the major increases in brain size (attributed to Homo sapiens). While it is true that $H$. sapiens represents a major increase in brain size compared with $H$. erectus, the brain size of $H$. erectus was also a major advance from previous hominids. $H$. erectus brains range between 850 to $900 \mathrm{~cm} 3$. A brain size of this magnitude is above Martin's (1983) threshold for requiring a shift to a humanlike pattern of brain and body growth: a great deal of postnatal brain development combined with slow growth of the body (Bogin, 2001). This results from limits on the size of the pelvic birth canal.

Corresponding to the increased brain size, $H$. erectus also represented a major advance in the use of technology (tools, fire, shelter) and social organization (Klein, 1989), presumably a reflection of major increases in general intelligence. We have seen that general intelligence is linked with adapting to new habitats. $H$. erectus was the first hominid species to disperse out of Africa into the temperate climates of Eurasia; within Africa, it colonized dry areas that had been unoccupied (Klein, 1989). There is thus little reason to reject the brain development hypothesis for explaining human life history characteristics based on what we know of $H$. erectus.

Hawkes et al.'s (2002) alternative hypothesis is that the basic trade-off is between the benefits of increased adult size (produced by a longer developmental period) and the risks of not reproducing as adulthood is delayed. As adult mortality declines, animals benefit from having a prolonged juvenile 
phase because it allows the animal to attain a greater body size. The difficulty with this hypothesis is the adolescent growth spurt. For the four primate species with sufficient data (humans, macaques, mangabeys, and chimpanzees), a growth spurt follows the termination of brain growth (Deaner et al., 2003). This is consistent with the hypothesis of inherent limits in brain growth, because the end of brain growth should permit body growth to be optimized while requiring less energy during the period when the brain is immature. However, if increased physical size were the focus of natural selection for humans, there would be no adolescent growth spurt. Instead, there would be a consistent pattern of growth until the optimum size was achieved, and it would be much earlier than in fact occurs in children. This is because, all things being equal, our ancestors would have benefited from attaining adult size as soon as possible. The fact that somatic growth is very slow during the period when children are still undergoing enormous increases in cognitive functioning followed by a period of rapid growth to attain adult physical size is much more compatible with brain development being the fundamental driving force of human development. Indeed, gorillas, with a much larger body size than humans, have a much shorter developmental period between weaning and maturity (see Hawkes et al., 2003, p. 217), indicating that attaining a large size in a much shorter period poses no insurmountable evolutionary problems. Reinforcing this argument is that fact that at all stages of the human life cycle after birth, humans have brains that are much larger than expected on the basis of body size (Bogin, 2000, p. 108). This conclusion fits well with Ward, Flinn, and Begun (2004), who show that changes in body size alone cannot explain changes in brain size, although they may well have worked synergistically to increase human ecological dominance; there must have been selection for intelligence itself.

The big picture, then, is that cognitive development is the critical force in human evolution. The vast gap in cognitive development between humans and other species can be seen from the fact that nonhuman primates do not progress to the level of a 3-year-old child (Langer, 2000); all human brain development beyond this point is via the process of terminal extension (e.g., Langer, 2000; McKinney, 2000). With the achievement of concrete operations in middle childhood and the onset of abstract reasoning ability around the time of puberty, children achieve the basics of adult level cognition as well as sexual competence (but not reproductive competence). Prior to adolescence, children are relatively inexpensive because of their small body size, because they contribute some economic benefit to the family (e.g., girls' babysitting), and because alloparents are available from other family members and relatives (Bogin, 1997; Hrdy, Ch. 6 , this volume). Children then undergo a growth spurt, thereby achieving the more energetically costly adult body size required for adult activities, such as fighting in men, childbirth (via increased pelvic size) in women, and obtaining 
material resources. Because of their adult level cognitive abilities, adolescents are able to rapidly absorb the culture around them and prepare to fit into the world of adults. Cognitive development continues after adolescence, however, ending only at around age 30, after which there are declines in fluid intelligence (Gibson, 1991; Langer, 2000; Paus et al., 1999).

Within this overall picture, there is an important role for plasticity: The most important general influence on long-term development is that lowered resource availability during development has the effect of prolonging development and decreasing adult stature and brain development (Gibson, 1991), although, as we have noted, brain development is relatively well buffered from such environmental influences. Indeed, captive chimpanzees attain menarche at earlier ages than wild chimpanzees, presumably as a result of better nutrition (Goodall, 1986). Modernization has resulted in better nutrition and health care, with the result that the average age of menarche has been declining for at least 150 years in Western societies. Life history theory converges on the proposition that for humans, cues to environmental adversity (poor nutrition, downward social mobility) would result in a delay of physical maturation and postponement of marriage and childbearing (MacDonald, 1997b, 1999).

\section{Conclusion}

The main "take-home” message is that attention to evolutionary theory results in an integration and enrichment of other theoretical perspectives in developmental psychology without eradicating them. Rather than an exclusive emphasis on domain-specific modules, there is a robust role for domain-general processes of intelligence and learning. There is a great deal of evidence for additive and nonadditive genetic variation in evolved systems and for correlations between genes and environments, but little evidence for interactions between evolved systems and environmental variation. There is also an important role for human plasticity in many developing systems. And perhaps most important, child development is seen as mainly the story of the development of the extraordinary human brain and our uniquely human domaingeneral cognitive abilities, which have resulted in the phenomenal cultural developments of the last several thousand years. 


\section{References}

Allman, J. M. (1999). Evolving brains. New York: Scientific American Library.

Anderson, B. (2000). The g factor in non-human animals. In G. R. Bock, J. A. Goode, \& K. Webb (Eds.), The nature of intelligence (pp. 79-95). New York: Wiley.

Bandura, A. (1969). Social learning theory of identificatory processes. In D. A. Goslin (Ed.), Handbook of socialization theory and research. New York: Rand-McNally.

Bandura, A. (1977). Social learning theory. Englewood Cliffs, NJ: Prentice Hall.

Belsky, J. Steinberg, L., \& Draper, P. (1991). Childhood experience, interpersonal development, and reproductive strategy: An evolutionary theory of socialization. Child Development, 62, 647-670.

Betzig, L. L. (1989). Causes of conjugal dissolution: A cross-cultural study. Current Anthropology, 30, 654-676.

Bjorklund, D., \& Pelligrini, A. (2002). The origins of human nature. Washington, DC: American Psychological Association.

Blurton Jones, N., \& Marlowe, F. W. (2002). Selection for delayed maturity: Does it take 20 years to learn to hunt and gather? Human Nature, 13, 199-238.

Bogin, B. (1997). Evolutionary hypotheses for human childhood. Yearbook of physical anthropology, 40, 63-89.

Bogin, B. (2000). Basic principles of human growth and development. In S. Stinson, B. Bogin, R. Huss-Ashmore, \& D. O’Rourke (Eds.), Human biology: An evolutionary and biocultural perspective (pp. 377-424). New York: Wiley-Liss.

Bogin, B. (2001). The growth of humanity. New York: Wiley-Liss.

Bouchard, T. J. (1993). The genetic architecture of human intelligence. In P. A. Vernon (Ed.), Biological approaches to the study of human intelligence (pp. 33-93). Norwood, NJ: Ablex.

Bowlby, J. (1969). Attachment and loss: Vol. I. Attachment. New York: Basic Books.

Boyd, R., \& Richerson, P. (1985). Culture and the evolutionary process. Chicago: University of Chicago Press.

Boyd, R., \& Richerson, P. (1988). An evolutionary model of social learning: The effects of spatial and temporal variation. In T. Zentall \& B. Galef (Eds.), Social learning: Psychological and biological perspectives (pp. 29-48). Hillsdale, NJ: Erlbaum.

Brazelton, T. B., Robey, J. S., \& Collier, G. A. (1969). Infant development in the Zinacanteco Indians of Southern Mexico. Pediatrics, 44, 274-290.

Buss, D. M. (1999). Evolutionary psychology. Boston: Allyn \& Bacon.

Campbell, D., Sanderson, R., \& Laverty, S. G. (1964). Characteristics of a conditioned response in human subjects during extinction trials following a simple traumatic conditioning trial. Journal of Abnormal and Social Psychology, 68, 627-639.

Capron, C., \& Duyme, M. (1989). Assessment of effects of socio-economic status on IQ in a full cross-fostering study. Nature, 340, 552-554.

Carpenter, P., Just, M., \& Shell, P. (1990). What one intelligence test measures: A theoretical account of the processing in the Raven Progressive Matrices Test. Psychological Review, 97, 404-431. 
Carroll, J. B. (1993). Human cognitive abilities. New York: Cambridge University Press.

Case, R. (1998). The development of conceptual structure. In W. Damon (Series Ed.) \& D. Kuhn \& R. S. Siegler (Vol. Eds.), Handbook of child psychology: Vol. 2. Cognition, perception, and language (5th ed., pp. 745-800). New York: Wiley.

Case, R., Demetriou, A., Platsidou, M., \& Kazi, S. (2001). Integrating concepts and tests of intelligence from the differential and developmental traditions. Intelligence, 29, 307-336.

Cattell, R. B. (1982). The inheritance of personality and ability: Research methods and findings. New York: Academic Press.

Cattell, R. B. (1963). Theory of fluid and crystallized intelligence: A critical experiment. Journal of Educational Psychology, 54, 1-22.

Chiappe, D., \& MacDonald, K. (2004). The evolution of domain-general mechanisms in intelligence and learning. . Journal of General Psychology 132(1), 5-40.

Cosmides, L., \& Tooby, J. (2002). Unraveling the enigma of human intelligence: Evolutionary psychology and the multimodular mind. In R. J. Sternberg \& J. C. Kaufman (Eds.), The evolution of intelligence (pp. 145-198). Mahwah, NJ: Erlbaum.

Cronbach, L. J., \& Snow, R. E. (1977). Aptitudes and instructional methods: A handbook for research on interactions. New York: Irvington.

Deaner, R. O., Barton, R. A., \& van Shaik, [should be Schaik] C. P. (2003). Primate brains and life histories: Renewing the connection. In P. M. Kappeler \& M. E. Pereira (Eds.), Primate life histories and socioecology (pp. 233-265). Chicago: University of Chicago Press.

DeFries, J. C., Plomin, R., \& Fulker, D. W. (Eds.). (1994). Nature and nurture during middle childhood. Cambridge, MA: Blackwell.

Deloache, J. S., Miller, K. F., \& S. L. Pierroutsakos, S. L. (1998). Reasoning and problem solving. In W. Damon (Series Ed.) \& D. Kuhn \& R. S. Siegler (Vol. Eds.), Handbook of child psychology: Vol. 2. Cognition, perception, and language (5th ed., pp. 801-850). New York: Wiley.

Demetriou, A., Elklides, A, \& Platsidou, M., (1993). The architecture and dynamics of the developing mind. Monographs of the Society for Research in Child Development, 58(5/6, Serial No. 234).

Demetriou, A., Christou, C., Spanoudis, G., \& Platsidou, M. (2002). The development of mental processing: Efficiency, working memory and thinking. Monographs of the Society for Research in Child Development, 67(1, Serial No. 268), 1-154.

Dennett, D. (1987). Cognitive wheels: The frame problem of AI. In Z. Pylyshyn (Ed.), The robot's dilemma (pp. 41-64). Norwood, NJ: Ablex.

Dennis, W. (1973). Children of the crèche. New York: Appleton.

Duncan, J., Burgess, P., \& Emslie, H. (1995). Fluid intelligence after frontal lobe lesions. Neuropsychologia, 33, 261-268.

Duncan, J., Emslie, H., Williams, P., Johnson, R., \& Freer, C. (1996). Intelligence and the frontal lobe: The organization of goal-directed behavior. Cognitive Psychology, 30, 257-303. 
Eaves, L. J., Last, K. A., Martin, N. G., \& Jinks, J. L. (1977). A progressive approach to non-additivity and genotype-environment covariance in the analysis of human differences. British Journal of Mathematical and Statistical Psychology, 30, 1-32.

Emmons, R. A. (1989). The personal striving approach to personality. In L. A. Pervin (Ed.), Goal concepts in personality and social psychology (pp. 87-126). Hillsdale, NJ: Erlbaum.

Fairbanks, L. A. (2000). Developmental timing of primate play. In S. T. Parker, J. Langer, \& M. L. McKinney (Eds.), Biology, brains, and behavior: The evolution of human development. Santa Fe, NM: School of American Research Press.

Falconer, D. S. (1981). Introduction to quantitative genetics (2nd ed.). London: Longman. Flavell, J. H. (1985). Cognitive development. Englewood Cliffs, NJ: Prentice Hall.

Fodor, J. A. (1983). The modularity of mind. Cambridge: MIT Press.

Fodor, J. A. (2000). The mind doesn't work that way. Cambridge: MIT Press.

Forsén, T., Eriksson, J., Tuomilehto, J., Reunanen, A., Osmond, C., \& Barker, D. (2000). The fetal and childhood growth of persons who develop Type 2 diabetes. Annals of Internal Medicine, 133, 176-182.

Fox, N. A. (1994). Dynamic cerebral processes underlying emotion regulation. In N. Fox (Ed.), The development of emotion regulation: Biological and behavioral considerations. Monographs for the Society for Research in Child Development, 59(2/3, Serial No. 240), 152-166.

Freedman, D. J., \& Freedman, N. C. (1969). Behavioral differences between Chinese-American and European-American newborns. Nature, 224, 1227.

Furstenberg, Frank F. (1991). As the pendulum swings: Teenage childbearing and social concern. Family Relations, 40, 127-138.

Galef, B. G. Jr. (1987). Social influences on the identification of toxic foods by Norway rats. Animal Learning and Behavior, 15, 327-332.

Gallistel, C. R. (1990). The organization of learning. Cambridge: MIT Press.

Gallistel, C. R. (1999). The replacement of general purpose learning models with adaptively specialized learning modules. In M. S. Gazzanigz (Ed.), The new cognitive neurosciences (2nd ed.). Cambridge: MIT Press.

Garcia, J., \& Koelling, R. (1966). Relation of cue to consequence in avoidance learning. Psychonomic Science, 4, 123-124.

Geary, D. C., \& Huffman, K. J. (2002). Brain and cognitive evolution: Forms of modularity and functions of mind. Psychological Bulletin, 128, 667-698.

Gelman, R., \& Baillargeon, R. (1983). A review of some Piagetian concepts. In J. H. Flavell \& E. Markman (Eds.), Handbook of child psychology: Vol. 3. Cognitive development. New York: Wiley.

Gelman, R., \& Williams, E. M. (1998). Enabling constraints for cognitive development and learning: Domain-specificity and epigenesis. In W. Damon (Series Ed.) \& D. Kuhn \& R. S. Siegler (Vol. Eds.), Handbook of child psychology: Vol. 2. Cognition, perception, and language (5th ed., pp. 575-630). New York: Wiley.

Gibson, K. R. (1991). Myelination and behavioral development. In K. R. Gibson \& A. C. Petersen (Eds.), Brain maturation and cognitive development: Comparative and cross-cultural perspectives (pp. 29-63). New York: Aldine de Gruyter. 
Goodall, J. (1986). The chimpanzees of Gombe: Patterns of behavior. Cambridge, MA: Harvard University Press.

Gottesman, I. I., \& Shields, J. (1982). Schizophrenia: The epigenetic puzzle. New York: Cambridge University Press.

Gottfredson, L. S. (1998). The general intelligence factor. Scientific American Presents, 9(4), 24-29.

Gottlieb, G. (1992). Individual development and evolution. New York: Oxford University Press.

Gottlieb, G. (1995). Some conceptual deficiencies in “developmental” behavior genetics. Human Development, 38, 131-141.

Gottlieb, G. (1991). Individual development and evolution: The genetics of novel behavior. Oxford, UK: Oxford University Press.

Gottlieb, G., Wahlsten, D., \& Lickliter, R. (1998). The significance of biology for human development: A developmental psychobiological systems view. In R. Lerner (Ed.), Handbook of child psychology: Vol. 1. Theoretical models of human development (pp. 233-273). New York: Wiley.

Greenough, W. T., \& Black, J. E. (1992). Induction of brain structure by experience: Substrates for cognitive development. In M. R. Gunnar \& C. A. Nelson (Eds.), Minnesota Symposia on Child Psychology: Vol. 24. Developmental behavioral neuroscience (pp. 155-200). Hillsdale, NJ: Erlbaum.

Hawkes, K., O’Connell, J. F., \& Blurton Jones, N. (2002). The evolution of human life histories: Primate trade-offs, grandmothering socioecology, and the fossil record. In P. M. Kappeler \& M. E. Pereira (Eds.), Primate life histories and socioecology, (pp. 204-227). Chicago: University of Chicago Press.

Heinrich, B. (2000). Testing insight in ravens. In C. Heyes and L. Huber (Eds.), The evolution of cognition (pp. 289-305). Cambridge: MIT Press.

Herrnstein, R. J., \& Murray, C. (1994). The bell curve: Intelligence and class structure in American life. New York: Free Press.

Hershberger, S. L. (1991, June). The underestimation of genotype-environment covariance by structural equation modeling methods. Paper presented at the meeting of the Behavior Genetics Association, St. Louis, MO.

Hershberger, S. L., Lichtenstein, P., \& Knox, S. S. (1994). Genetic and environmental influences on perceptions of organizational climate. Journal of Applied Psychology, 79, 24-33.

Horn, J. L., \& Hofer, S. M. (1992). Major abilities and development in the adult period. In R. J. Sternberg \& C. A. Berg (Eds.), Intellectual development. New York: Cambridge University Press.

Jinks, J. L., \& Fulker, D. W. (1970). Comparison of the biometrical genetical, MAVA, and classical approaches to the analysis of human behavior. Psychological Bulletin, 73, 311-349.

Kail, R. (1991). Developmental change in speed of processing during childhood and adolescence. Psychological Bulletin, 109, 490-501. 
Kail, R. (1996). Nature and consequences of developmental change in speed of processing. Swiss Journal of Psychology, 55, 133-138.

Kalat, J. W. (1985). Taste-aversion learning in ecological perspective. In T. Johnston \& A. Pietrewicz (Eds.), Issues in the ecological study of learning (pp. 119-141). Hillsdale, NJ: Erlbaum.

Kaplan, H., Hill, K., Lancaster, J., \& Hurtado, A. M. (2000). A theory of human life history evolution: Diet, intelligence, and longevity. Evolutionary Anthropology, 9, 156-185.

Kempthorne, O. (1957). Introduction to genetic statistics. Ames, IA: Iowa State Press.

Klein, R. G. (1989). The human career: Human biological and cultural origins. Chicago: University of Chicago Press.

Kohn, B., \& Dennis, M. (1972). Observation and discrimination learning in the rat: Specific and non-specific effects. Journal of Comparative and Physiological Psychology, 78, 292-296.

Laland, K. N., Odling-Smee, J., \& Feldman, M. W. (2000). Niche construction, biological evolution and cultural change. Behavioral and Brain Sciences, 23, 131-175.

Langer, J. (2000). The heterochronic evolution of primate cognitive development. In S. T. Parker, J. Langer, \& M. L. McKinney (Eds.), Biology, brains, and behavior: The evolution of human development. Santa Fe, NM: School of American Research Press.

Lautch, H. (1971). Dental phobia. British Journal of Psychiatry, 119, 151-158.

Leonard, W. R., \& Robertson, M. L. (1994). Evolutionary perspectives on human nutrition: The influence of brain and body size on diet and metabolism. American Journal of Human Biology, 6, 77-88.

Lerner, R. (Ed.). (1998). Handbook of child psychology: Vol. 1. Theoretical models of human development. New York: Wiley.

Li, S. (2003). Biocultural orchestration of developmental plasticity across levels: The interplay of biology and culture in shaping the mind and behavior across the life span. Psychological Bulletin, 129, 171-194.

Lickliter, R., \& Honeycutt, H. (2003). Developmental dynamics: Toward a biologically plausible evolutionary psychology. Psychological Bulletin, 129, 819-835.

Lien, N. M., Meyer, K. K., \& Winick, M. (1977). Early malnutrition and "late” adoption: A study of their effects on the development of Korean orphans adopted into American families. American Journal of Clinical Nutrition, 30, 1734-1739.

Lusk, J., MacDonald, K., \& Newman, J. R. (1998). Resource appraisals among self, friend and leader: Implications for an evolutionary perspective on individual differences and a resource/reciprocity perspective on friendship. Personality and Individual Differences, 24, 685-700.

Lynn, R. (1996). Dysgenics: Genetic deterioration in modern populations. Westport, CT: Praeger.

Maccoby, E., \& Martin, J. (1983). Socialization in the context of the family. In P. H. Mussen (Series Ed.) \& E. M. Hetherington (Vol. Ed.), Handbook of child psychology: Vol. 4. Socialization, personality, and social development (pp. 1102). New York: Wiley. 
MacDonald, K. B. (1988a). The interfaces between developmental psychology and evolutionary biology. In K. B. MacDonald (Ed.), Sociobiological perspectives on human development. New York: Springer-Verlag.

MacDonald, K. B. (1988b). Social and personality development: An evolutionary synthesis. New York: Plenum.

MacDonald, K. B. (1991). A perspective on Darwinian psychology: The importance of domain-general mechanisms, plasticity, and individual differences. Ethology and Sociobiology, 12, 449-480.

MacDonald, K. B. (1992). Warmth as a developmental construct: An evolutionary analysis. Child Development, 63, 753-773.

MacDonald, K. B. (1995a). Evolution, the five factor model, and levels of personality. Journal of Personality 63, 525-567.

MacDonald, K. B. (1995b). The establishment and maintenance of socially imposed monogamy in Western Europe. Politics and the Life Sciences, 14, 3-23.

MacDonald, K. B. (1997a). The coherence of individual development: An evolutionary perspective on children's internalization of parental values. In J. Grusec \& L. Kuczynski (Eds.), Parenting and children's internalization of values: A handbook of contemporary theory (pp. 362-397). New York: Wiley.

MacDonald, K. B. (1997b). Life history theory and human reproductive behavior: Environmental/contextual influences and heritable variation. Human Nature, 8, 327-359.

MacDonald, K. B. (1998). Evolution, culture, and the five-factor model. Journal of CrossCultural Psychology, 29, 119-149.

MacDonald, K. B. (1999). An evolutionary perspective on human fertility. Population and Environment, 21(2), 223-246.

Martin, R. D. (1983). Human brain evolution in an ecological context. Fifty-second James Arthur Lecture. New York: American Museum of Natural History.

Mascie-Taylor, C. G. N., \& Bogin, B. (1995). Human variability and plasticity. Cambridge, UK: Cambridge University Press.

Mcclearn, G., Johansson, B., Berg, S., Pedersen, N. L., Ahern, F., Petrill, S. A., \& Plomin, R. (1997). Substantial Genetic Influence on Cognitive Abilities in Twins 80 or More Years Old. Science, 276, 1560-1563.

McGue, M., Bouchard, T. J., Iacono, W. G. Jr., \& Lykken, D. T. (1993). Behavioral genetics of cognitive ability: A lifespan perspective. In R. Plomin \& G. E. McClearn (Eds.), Nature, nurture, and psychology (pp. 59-76). Washington, DC: American Psychological Association.

McGue, M., \& Lykken, D. T. (1992). Genetic influence on risk of divorce. Psychological Science, 3, 368-373.

McKinney, M. L. (2000). Evolving behavioral complexity by extending development. In S. T. Parker, J. Langer, \& M. L. McKinney (Eds.), Biology, brains, and behavior: The evolution of human development. Santa Fe, NM: School of American Research Press.

Molenaar, P. C., \& Boomsma, D. I. (1987). Application of nonlinear factor analysis to genotype-environment interaction. Behavior Genetics, 17, 71-80. 
Moos, R. H. (1981). Work environment scale manual. Palo Alto, CA: Consulting Psychologists Press.

Moos, R. H., \& Moos, B. H. (1981). Family environment scale manual. Palo Alto, CA: Consulting Psychologists Press.

Morgan, B., \& Gibson, K. R. (1991). Nutrition and environmental interactions in brain development. In K. R. Gibson \& A. C. Petersen (Eds.), Brain maturation and cognitive development: Comparative and cross-cultural perspectives (pp. 91106). New York: Aldine De Gruyter.

Öhman, A., \& Mineka, S. (2001). Fears, phobias, and preparedness: Toward an evolved module of fear and fear learning. Psychological Review, 108, 483-522.

Orlick, T., Zhou, Q., \& Partington, J. (1990). Co-operation and conflict within Chinese and Canadian kindergarten settings. Canadian Journal of Behavioural Sciences, 22, 20-25.

Pinker, S. (1994). The language instinct. New York: William Morrow.

Plomin, R. (2003). Genes, genomics, and g. Molecular Psychiatry, 8, 1-5.

Plomin, R., \& DeFries, J. C. (1985). Origins of individual differences in infancy: The Colorado Adoption Project. Orlando, FL: Academic Press.

Plomin, R., DeFries, J. C., \& Fulker, D. W. (1988). Nature and nurture during infancy and early childhood. New York: Cambridge University Press.

Plomin, R., DeFries, J. C., \& Loehlin, J. C. (1977). Genotype-environment interaction and correlation in the analysis of human behavior. Psychological Bulletin, 84, 309322.

Potts, R. (1998). Variability selection in Hominid evolution. Evolutionary Anthropology, 7, 81-96.

Rescorla, R. A. (1980). Pavlovian second-order conditioning: Studies in associative learning. Hillsdale, NJ: Erlbaum.

Rescorla, R. A. (1988). Pavlovian conditioning: It's not what you think it is. American Psychologist, 43, 151-160.

Revulsky, S. (1985). The general process approach to animal learning. In T. D. Johnston \& A. T. Pietrewicz (Eds.), Issues in the ecological study of learning (pp. 401432). Hillsdale, NJ: Erlbaum.

Roberts, D. F. (1995). The pervasiveness of plasticity. In C. G. Mascie-Taylor \& B. Bogin (Eds.), Human variability and plasticity (pp. 1-17). Cambridge, UK: Cambridge University Press.

Rowe, D. C. (1994). The limits of family influence: Genes, experience, and behavior. New York: Guilford Press.

Rutter, M., \& Silberg, J. (2002). Gene-environment interplay in relation to emotional and behavioral disturbance. In S. T. Fiske (Ed.), Annual Review of Psychology, 53, 463-490.

Scarr, S. (1995). Commentary. Human Development, 38, 154-158.

Scarr, S., \& R. Weinberg, (1983). The Minnesota adoption studies: Genetic differences and malleability. Child Development 54, 260-267. 
Schell, L. M., (1995). Human plasticity, history, and future research. In C. G. MascieTaylor \& B. Bogin (Eds.), Human variability and plasticity (pp. 213-237). Cambridge, UK: Cambridge University Press.

Segal, N., \& MacDonald, K. B. (1998). Behavior genetics and evolutionary psychology: A unified perspective on personality research. Human Biology 70, 159-184.

Seligman, M. E. P. (1971). Phobias and preparedness. Behavior Therapy, 2, 307-320.

Shams, M., \& Williams, R. (1997). Generational changes in height and body mass differences between British Asians and the general population in Glasgow. Journal of Biosocial Science, 29, 101-109.

Shanks, D. R. (1994). Human associative learning. In N. J. Mackintosh (Ed.), Animal learning and cognition (pp. 335-374). San Diego: Academic Press.

Shettleworth, S. (1994). Biological approaches to the study of learning. In N. J. Mackintosh (Ed.), Animal learning and cognition (pp. 185-219). San Diego: Academic Press.

Shonkoff, J. P., \& Phillips, D. A. (2000). From neurons to neighborhoods: The science of early childhood development. Washington, DC: National Academy Press.

Spelke, E., \& Newport, E. (1998). Nativism, empiricism and the development of knowledge. In R. M. Lerner (Vol. Ed.), Handbook of child psychology: Vol. 1. Theoretical models of human development (pp. 275-340). New York: Wiley.

Staddon, J. E. R. (1988). Learning as inference. In R. C. Bolles \& M. D. Beecher (Eds.), Learning and evolution (pp. 59-78). Hillsdale, NJ: Erlbaum.

Stevens, R. (1998). Nutrition and cognitive development. In S. Ulijasek et al. (Eds.), Cambridge encyclopedia of growth and development. Cambridge, UK: Cambridge University Press.

Stoch, M. B., Smythe, P. M., Moodie, A. D., \& Bradshaw, D. (1981). Psychosocial outcome and CT findings after gross undernourishment during infancy: A 20-year developmental study. Developmental Medicine and Child Neurology, 24, 419436.

Thelen, E. (1995). Motor development: A new synthesis. American Psychologist, 50, 7995.

Tomasello, M. (1999). The culture origins of human cognition. Cambridge, MA: Harvard University Press.

Tooby, J. \& Cosmides, L. (1990). On the universality of human nature and the uniqueness of the individual: The role of genetics and adaptation. Journal of Personality, 58, $17-67$.

Tooby, J., \& Cosmides, L. (1992). The psychological foundations of culture. In J. Barkow, L. Cosmides, \& J. Tooby (Eds.), The adapted mind: Evolutionary psychology and the generation of culture (pp. 19-136). New York: Cambridge University Press.

Turkheimer, E., Goldsmith, H. H., \& Gottesman, I. I. (1995). Commentary-Some conceptual deficiencies in 'developmental' behavior genetics. Human Development, 38, 142-153.

Turkheimer, E., Lovett, G., Robinette, C. D., \& Gottesman, I. (1992). The heritability of divorce: New data and theoretical implications. Behavior Genetics, 22, 757 (Abstract). 
72 Evolutionary Perspectives on Human Development

Wahlsten, D. (1990). Insensitivity of the analysis of variance to heredity-environment interaction. Behavioral and Brain Sciences, 13, 109-161.

Ward, C. V., Flinn, M. V., \& Begun, D. (2004). Body size and intelligence in Hominoid evolution. In A. E. Russon \& D. R. Begun (Eds.), The evolution of thought: Evolutionary origins of great ape intelligence. Cambridge, UK: Cambridge University Press.

Weinberg, R. A., Scarr, S., \& Waldman, I. D. (1992). The Minnesota Transracial Adoption Study: A follow-up of IQ test performance at adolescence. Intelligence, 16, 117-135.

Weisfeld, G. (1997). Research on emotions and future developments in human ethology. In A. Schmitt, K. Atzwanger, K. Grammer, \& K. Schäfer (Eds.), New aspects of human ethology (pp. 25-46). New York: Plenum.

West-Eberhard, M. J. (1989). Phenotypic plasticity and the origins of diversity. Annual Review of Ecology and Systematics, 20, 249-278.

West-Eberhard, M. J. (2003). Developmental plasticity and evolution. New York: Oxford University Press.

Wilson, E. O. (1975). Sociobiology: The new synthesis. Cambridge, MA: Harvard University Press.

Winick, B., Meyer, K. K., \& Harris, R. (1975). Malnutrition and environmental enrichment by early adoption. Science, 190, 1173-1175. 